\title{
The Influence of the Ocean on Typhoon Nuri (2008)*
}

\author{
JINGRU SUN \\ Center for Earth System Science, Tsinghua University, Beijing, China \\ LIE-YAUW OEY \\ Institute of Hydrological and Oceanic Sciences, and Atmospheric Science Department, National Central University, \\ Taoyuan County, Taiwan, and Atmospheric and Oceanic Sciences Program, Princeton \\ University, Princeton, New Jersey
}

(Manuscript received 20 January 2015, in final form 12 June 2015)

\begin{abstract}
Typhoon Nuri (2008) was 1 of approximately 120 typhoons in the past 60 years that passed through a narrow gap, the Luzon Strait, connecting the western North Pacific and the South China Sea (SCS). In total $70 \%$ of these storms, including Nuri, reached their maximum intensities over the warm waters east of Luzon and in the Kuroshio, then rapidly weakened in the SCS. Numerical experiments were conducted to understand the intensity change of Nuri. Westward across the Kuroshio in the Luzon Strait, the $26^{\circ} \mathrm{C}$ isotherm shallows rapidly by half. This and stronger mixing by wind-ocean resonance preferentially cooled sea surface temperature and weakened the typhoon in SCS. A positive-feedback mechanism is then described to explain the intensification of Nuri over the western North Pacific.
\end{abstract}

\section{Introduction}

Typhoon Nuri began as a tropical depression on 17 August 2008 near $15^{\circ} \mathrm{N}, 140^{\circ} \mathrm{E}$ in the Philippine Sea in the western North Pacific (Fig. 1) (Montgomery and Smith 2012). The storm formed over a region in the western Pacific warm pool where the depth of the $26^{\circ} \mathrm{C}, Z_{26}$, was thick, exceeding $100 \mathrm{~m}$ (Fig. 1a); the corresponding ocean heat content (Leipper and Volgenau 1972) exceeds $100 \mathrm{~kJ} \mathrm{~cm}^{-2}$. These ocean conditions were conducive to cyclogenesis and storm intensification (DeMaria and Kaplan 1994). Nuri became a typhoon at 1200 UTC 18 August 2008 and continued to intensify as the storm moved rapidly $\left(7 \mathrm{~m} \mathrm{~s}^{-1}\right)$ over the warm pool. Nuri reached peak intensity as a category 3 typhoon on 20 August when it crossed the Kuroshio east of the Luzon Strait near $122^{\circ} \mathrm{E}$. The storm slowed down $\left(5 \mathrm{~m} \mathrm{~s}^{-1}\right)$ and weakened as it moved

\footnotetext{
* Supplemental information related to this paper is available at the Journals Online website: http://dx.doi.org/10.1175/MWR-D-15-0029.s1.

Corresponding author address: L.-Y. Oey, National Central University, IHOS and Atmospheric Science Dept., No.300, Zhongda Rd., Jhongli City, Taoyuan County 320, Taiwan.

E-mail: lyooey@gmail.com
}

across South China Sea where the $Z_{26}$ was shallower, below $60 \mathrm{~m}$. Nuri made a direct hit on Hong Kong in the early morning of 22 August as a category 1 typhoon.

According to the data from the International Best Track Archive for Climate Stewardship (IBTrACS), Typhoon Nuri was one but about 129 typhoons in the past 63 years that passed through the Luzon Strait into the South China Sea, about $70 \%$ of which reached their maximum intensities in the warm waters east of Luzon and in the Kuroshio before weakening in the South China Sea (Fig. 2a), which may indicate some common underlying physical causes. This intensity change was also evident for tracks away from terrains north of Luzon and south of Taiwan, suggesting ocean influences (Fig. 2b). The importance of sea surface temperature (SST) and upper-ocean thermal structure in affecting tropical cyclone (TC) intensity has previously been documented (Schade and Emanuel 1999; Lin et al. 2008; Emanuel et al. 2004). Strong turbulence is produced in the upper ocean over which the storm passes, mixing and entraining subsurface waters with cooler temperature to the sea surface, reducing the SST (Price 1981). Cooling of SST of $2.5 \mathrm{~K}$ near the core of a tropical cyclone can effectively shut down the energy production and either weakens or destroys it (Emanuel 1999). 

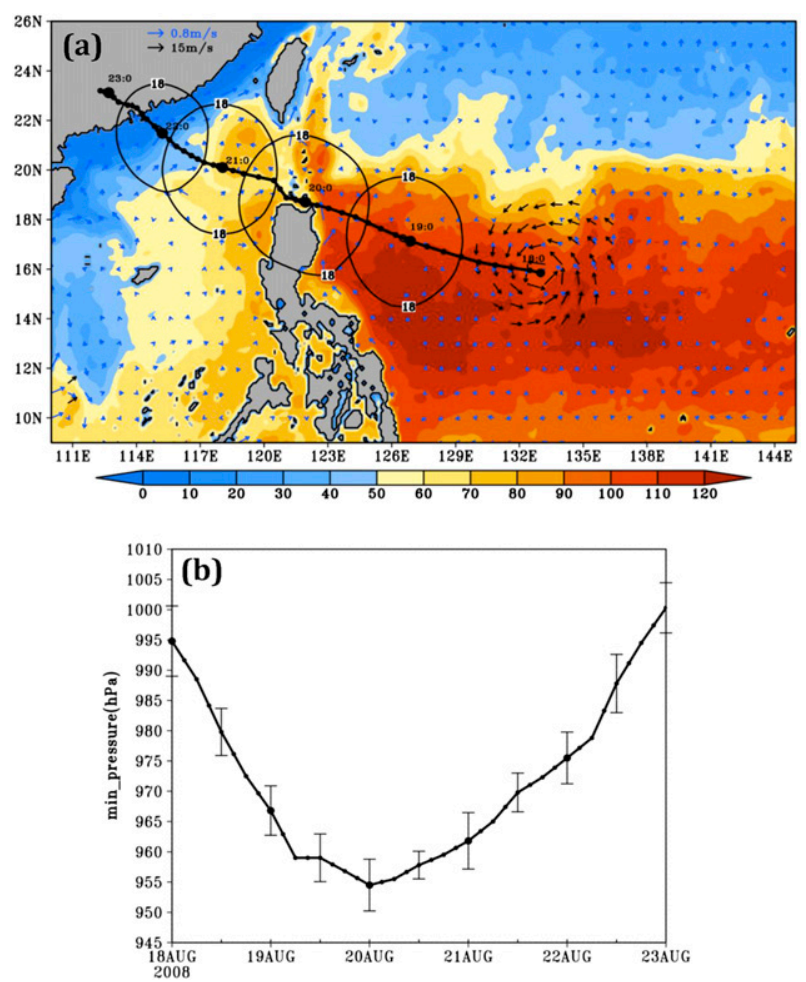

FIG. 1. (a) Track of Typhoon Nuri marked daily during 18-23 Aug 2008 in the western North Pacific Ocean. Color shading is the depth of $26^{\circ} \mathrm{C}$ isotherm, $Z_{26}(\mathrm{~m})$, on $18 \mathrm{Aug} 2008$. Black and blue vectors are analysis wind and ocean current velocities on the same date. Vectors are plotted every 25 (wind) and 10 (current) grid points, for speeds exceeding 10 and $0.1 \mathrm{~m} \mathrm{~s}^{-1}$ for wind and ocean currents, respectively; vector scales are shown at the top left. Circles are contours of wind speed $=18 \mathrm{~m} \mathrm{~s}^{-1}$ on 19-22 Aug. (b) Typhoon Nuri minimum center pressure from IBTrACS observation, during 18-23 Aug 2008. Vertical bars show the standard errors.

In this study, we present a case study of Typhoon Nuri (2008) using the Weather Research and Forecasting (WRF) Model (Michalakes et al. 2001). Apart from the scientific curiosity of explaining the intensity change, a practical motivation of the present study is that nearly all of the storms that passed into South China Sea eventually made landfalls, mostly along southern China, causing immense economic losses and human sufferings (Elsner and Liu 2003). A case study of Nuri may shed light into the processes that control the typhoon's intensity in the South China Sea, which may lead to improved forecasts.

Forecasts of tracks of tropical cyclones have steadily improved over the past few decades, but intensity forecasts have not improved significantly (Rogers et al. 2006; Houze et al. 2007; Rappaport et al. 2009; Gall et al. 2013; Rios-Berrios et al. 2014). The reason may be because track prediction depends more on large-scale processes, but intensity depends on inner-core dynamics and the environment (Marks and Shay 1998; Houze et al. 2007).
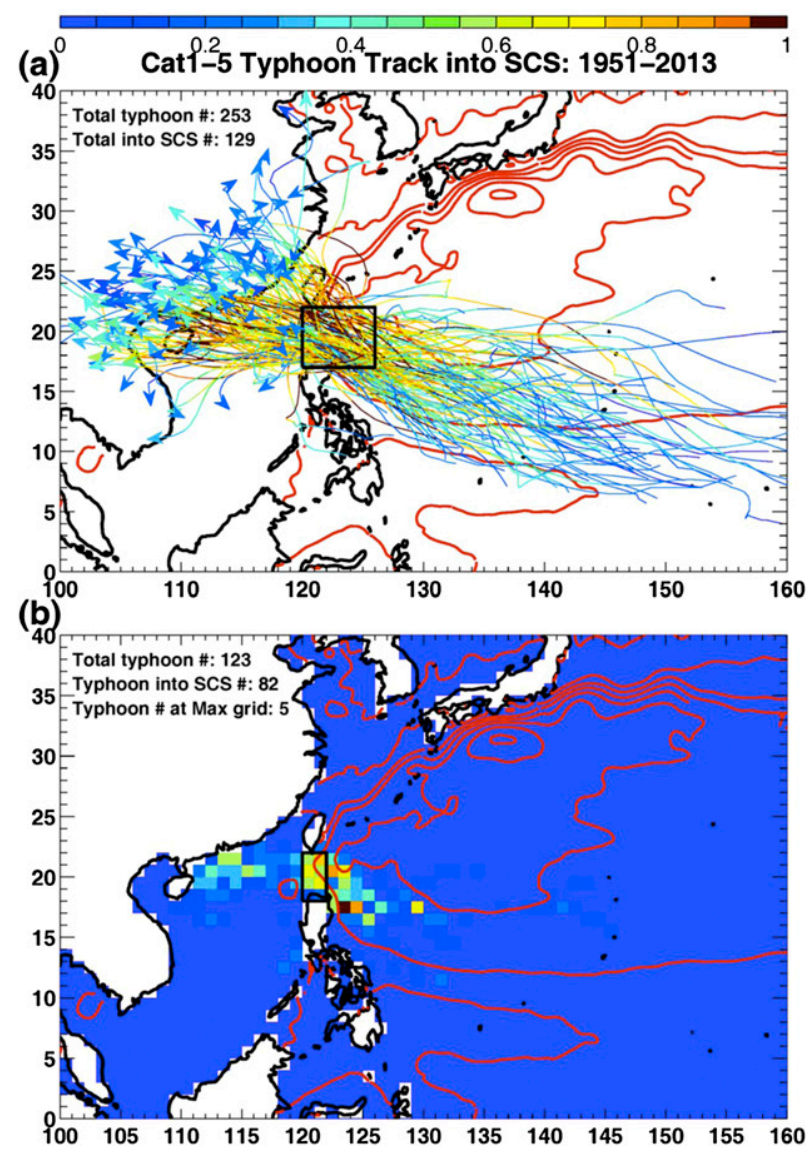

FIG. 2. (a) Tracks from IBTrACS observations of typhoons that passed through the "Luzon box" shown east of the Luzon Strait during 1951-2013. For each track, colors show 6-hourly wind speeds normalized by the maximum wind speed for that track. The darkest brown color then corresponds to normalized wind speeds $>0.95$, and indicates where and when the typhoons were near their maximum intensities. A total of 253 typhoons passed through the Luzon box; 129 went into the South China Sea and those are displayed here. (The remaining veered north toward northern China, Korea, and/or Japan). In total 96 of the 129 reached their peak intensities east of Luzon, while the remaining 33 were inside the South China Sea mostly over the northwestern shelf. Red contours show the ocean's mean absolute dynamic topography MADT $(\mathrm{m}$; interval $=0.1 \mathrm{~m}$, contour off Luzon $=1.3 \mathrm{~m})$ from AVISO (http://www.aviso.oceanobs.com/). (b) Frequency of peak intensity (normalized by the maximum $=5$ ) in $1^{\circ} \times 1^{\circ}$ grid according to tracks shown in (a), except that those tracks within $50 \mathrm{~km}$ of the northern (southern) tip of Luzon (Taiwan) were excluded. In this case, 58 (71\%) typhoons reached their peak intensities just east of the Luzon Strait. The remaining 24 peaked over the northwestern shelf of the South China Sea. (Figure courtesy of Mr. Simon Chao.)

To improve TC intensity forecasts, many studies examined sensitivities of TC intensity to 1) microphysics schemes (Wang 2002; Zhu and Zhang 2006; Li and Pu 2008); 2) boundary layer parameterizations (Braun and Tao 2000; Green and Zhang 2013); 3) grid resolutions and cloudresolving models (Davis et al. 2008; Zhang et al. 2009); and 4) 


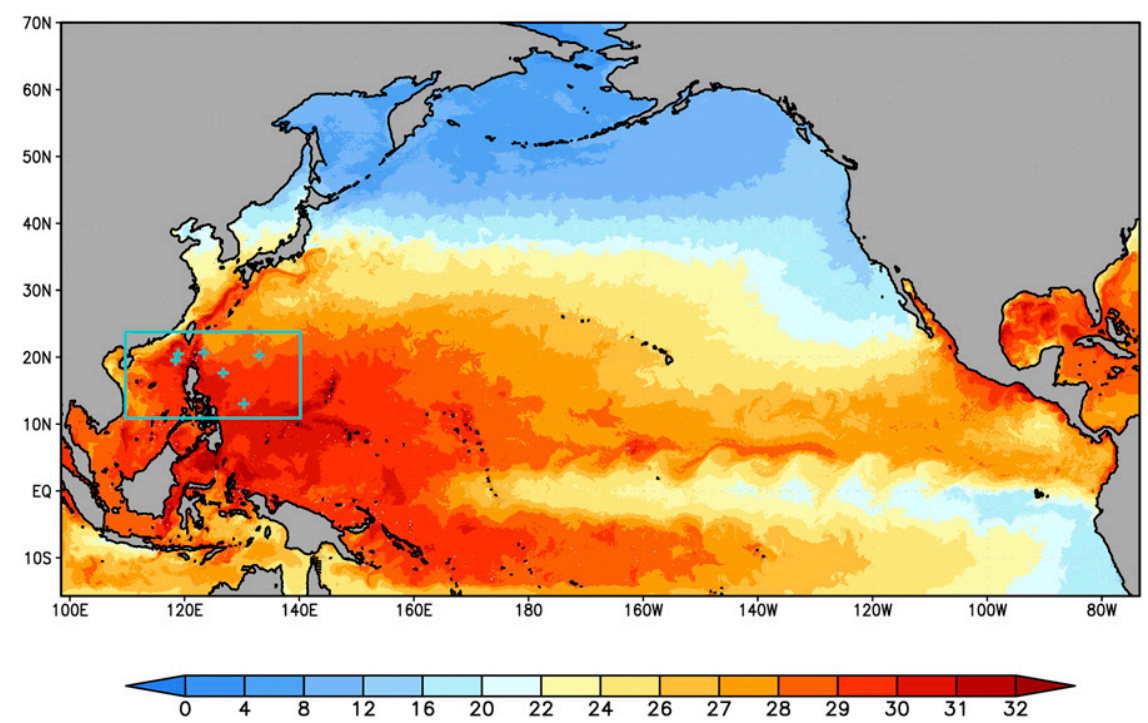

FIG. 3. The North Pacific Ocean POM model domain showing the simulated SST (shading in ${ }^{\circ} \mathrm{C}$ ) on 16 Aug 2008. The blue rectangle is the WRF fine-grid model domain used for Nuri simulation. The pluses "+" inside the WRF domain show the positions of example Argo (freedrifting profiling floats that measure the temperature and salinity of the upper $2000 \mathrm{~m}$ of the ocean; http://www-argo.ucsd.edu/) stations where detailed observed profiles are compared with model in the online supplemental material. They and all Argo data during Nuri in the WRF domain were also used in the online supplemental material to compare with the upper-ocean thermal structures simulated by POM.

wind shear, translational speed, and environmental humidity (Zeng et al. 2007; Hill and Lackmann 2009). Emanuel (1999, p. 665) concluded that “ ... much of the evolution of storm intensity is controlled by its initial intensity together with the thermodynamic properties of the atmosphere and upper ocean along the storm track." Consistent with the previous findings, we found that although the track of Nuri could be quite accurately simulated and was relatively insensitive to different microphysics schemes and SSTs used, its intensity change was highly sensitive to SSTs, which in turn were closely tied to the ocean dynamics of the western North Pacific and the South China Sea.

The main goal then is to understand the factors that controlled the intensity change of Nuri. We conducted a series of experiments to understand the storm's sensitivity to different microphysics parameterizations and SSTs. We then attempted to explain the intensity change based on the idea of potential vorticity (PV) generation by diabatic heating and friction (Stoelinga 1996). We will show that ocean dynamics largely determined the storm's intensity. We also examined the possible influence of the large-scale environmental wind shear. We found that in the Nuri case the wind shear could not be the main factor influencing the intensity change, but it controlled the precipitation pattern according to the pattern described by Chen et al. (2006). The following writing is organized as follows. Section 2 describes the
WRF Model, sensitivity experiments and the ocean model. Section 3 presents the results. Section 4 describes Nuri's intensification in terms of $\mathrm{PV}$, and section 5 provides the conclusions and a discussion.

\section{The WRF Model and experiments}

The WRF Model (WRF-ARW; http://www.wrf-model. org/index.php) was used to simulate Nuri. WRF is a compressible, nonhydrostatic mesoscale model on the Arakawa $\mathrm{C}$ grid, and uses the terrain-following sigma grid in the vertical. A single fine-grid domain was used (Fig. 3): from $10^{\circ}-24^{\circ} \mathrm{N}$ to $110^{\circ}-140^{\circ} \mathrm{E}$ and with the same grid size $\Delta=4 \mathrm{~km}$ in longitude ( $x$ direction) and latitude ( $y$ direction), comparable to or slightly coarser than the 1.3312-km resolutions used in the literature (e.g., Davis et al. 2008; Li and Pu 2008; Hill and Lackmann 2009; Zhang et al. 2009; Hendricks et al. 2013). There were 28 sigma levels in the vertical: $1.000,0.993,0.983,0.970,0.954$, $0.934,0.909,0.880,0.830,0.779,0.729,0.678,0.592,0.514$, $0.443,0.380,0.324,0.273,0.228,0.188,0.153,0.121,0.094$, $0.069,0.048,0.030,0.014$, and 0.000 . The nudging option in WRF was turned off. Lateral open boundary conditions of the fine-grid model were specified using the National Centers for Environmental Prediction (NCEP) Final (FNL) Operational Global Analysis data throughout the 5-day simulation from 0000 UTC 18 August to 0000 UTC 
TABLE 1. WRF Model experiments.

\begin{tabular}{llllcc}
\hline \hline Expt No. & Expt names & Microphysics schemes & \multicolumn{1}{c}{ SST } & PBL scheme & Cumulus scheme \\
\hline 1 & ncep_KS & KS & NCEP RTG_SST & YSU & KF \\
2 & ncep_LIN & LIN & NCEP RTG_SST & YSU & KF \\
3 & ncep_Eta & Eta & NCEP RTG_SST & YSU & KF \\
4 & nce__WSM6 & WSM6 & NCEP RTG_SST & YSU & KF \\
5 & ncep_SBU & SBU-YLIN & NCEP RTG_SST & YSU & KF \\
6 & ghr_KS & KS & GHRSST & YSU & KF \\
7 & pom_KS & KS & North Pacific POM & YSU & KF \\
$8-12$ & pom__KS & KS & Perturbed POM & YSU & KF \\
13 & pom_LIN & LIN & North Pacific POM & YSU & KF \\
14 & pom_Eta & Eta & North Pacific POM & YSU & KF \\
15 & pom_WSM6 & WSM6 & North Pacific POM & YSU & KF \\
16 & pom_SBU & SBU-YLIN & North Pacific POM & YSU & KF \\
& E_ncep & Expts 1-5 & NCEP RTG_SST & YSU & KF \\
& E_pom & KS & Expts 7-12 & YSU & KF \\
& E_pomMP & Expts 7, 13-16 & Expts 7-12 & YSU & KF \\
\hline
\end{tabular}

23 August 2008. The analysis data were available every $6 \mathrm{~h}$ on $1^{\circ} \times 1^{\circ}$ global grid. The global data were interpolated onto the fine-grid domain to initialize the simulation at 0000 UTC 18 August [as in Davis et al. (2008) for Hurricane Katrina (2005)]. We focus on studying the sensitivity of the simulated Nuri intensity to upperocean thermal structures and internal variability, and the same initial condition based on the NCEP data was used for all experiments.

The same planetary boundary layer (PBL) parameterization based on the Yonsei University (YSU) scheme of Hong et al. (2006) and convective parameterization scheme based on the new Eta (Kain-Fritsch) scheme of Kain and Fritsch (1990) and Kain (2004) were also used in all the sensitivity experiments. These schemes were used by Davis et al. (2008) and the YSU scheme was used by Zhang et al. (2009) and $\mathrm{Li}$ and Pu (2008). To separate effects of internal variability and ocean conditions on the intensity of the storm, three sets of experiments were conducted. In the first set, simulations were carried out with five different microphysics parameterizations, but the SST was the same using the NCEP realtime global (RTG) SST data (Table 1, experiments 1-5). Microphysics schemes affect latent heat release of the simulated typhoon, and therefore, also inner-core dynamics. These simulations served therefore to test the sensitivity of the simulated intensity to the internal variability of Nuri. The five microphysics schemes were Kessler warmrain scheme (KS; Kessler 1969), the Purdue-Lin scheme (LIN), the Eta Ferrier scheme (Ferrier et al. 2002), the WRF single-moment 6-class (3-class ice) microphysics scheme (WSM6; Hong and Lim 2006), and the Stony Brook University (SBU-YLIN) scheme (Lin and Colle 2011). In the second set of experiments, the microphysics scheme was fixed using the KS scheme, but three different SST datasets were used: NCEP RTG_SST,
Group for High Resolution SST (GHRSST), the North Pacific Princeton Ocean Model (POM) SST (Oey et al. 2013, 2014) (Table 1, experiments 1, 6, and 7), and perturbed SSTs from the ocean model (Table 1, experiments 8-12). Both GHRSST and POM SST were 3-hourly data while NCEP was daily, and in each case the SST was linearly interpolated at each time step into WRF. In the third set, the pom_KS experiment (7, Table 1) was repeated but using the other four microphysics schemes LIN, Eta, WSM6, and SBU (Table 1, experiments 1316). The ensemble average of experiments $1-5$ is referred to as E_ncep, that of experiments 7-12 is called E_pom, and finally the ensemble average of experiments 7 and $13-16$ is called E_pomMP.

The above experiments were designed so that each differed from the other by one and only one input (SST) or microphysical scheme, but were otherwise identical. This strategy allowed unambiguous interpretations of the origins of differences between any two experiments; different intensities of ncep_KS and pom_KS, for example, arose because of the different SSTs used, regardless of how complicated the resulting processes might be. In the case of Nuri, the KS scheme will be seen to yield intensity change which agreed best with observations, and we will use it as our control experiment.

\section{The SST from a North Pacific Ocean model}

The NCEP RTG_SST and GHRSST are reanalysis data that, as we will show, introduce large errors when used to simulate Nuri. To account for the dynamical evolution of the upper-ocean state due to the storm, we ran the North Pacific Ocean model of Oey et al. (2013, 2014) which then provided the SST for Nuri simulation using WRF. Details are given in the online supplemental material (SM), and a more complete discussion of ocean response due to Nuri is given in Sun et al. (2015). 


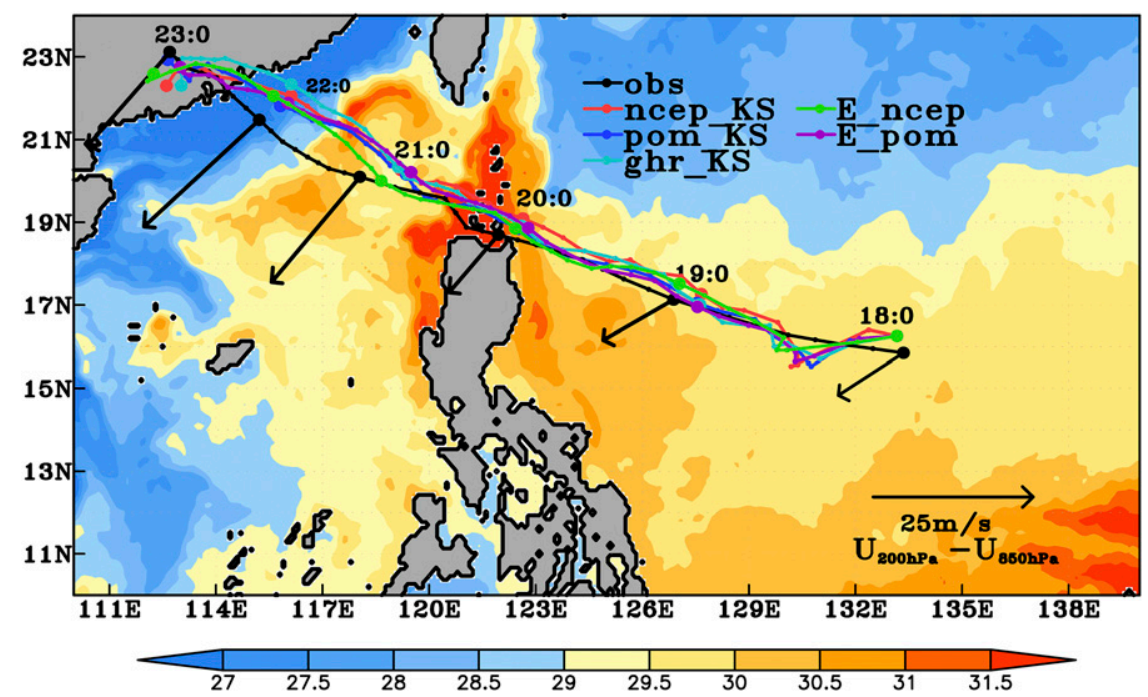

FIG. 4. Typhoon Nuri track from observations (average of all available tracks reported by different forecasting centers in the IBTrACS dataset), three control experiments (ncep_KS, pom_KS, and ghr_KS), and two ensembles (E_ncep and E_pom) during 18-23 Aug 2008. Color shading is POM SST at the initial time of Typhoon Nuri on 18 Aug 2008; large (small) filled symbols mark daily ( 3 hourly) positions. The vector "wind shear" $\mathbf{V}_{s}=\mathbf{U}_{200 \mathrm{hPa}}-\mathbf{U}_{850 \mathrm{hPa}}$ $\left(\mathrm{m} \mathrm{s}^{-1}\right)$ is plotted daily.

Air-sea coupling was excluded in the present study; instead, the SST in the WRF simulation of Nuri was obtained from 3-hourly outputs of the ocean model forced by the TC wind of the same intensity and track as the observed storm (see below), so that the wind forcing on the ocean is as realistic as possible short of a complete measured wind field. As will be shown below, with accurate SST, the uncoupled run could simulate the intensity change that compared well with the observation. Nonetheless, recent studies have shown the importance of ocean and surface waves on tropical cyclone boundary layer and structure (Lee and Chen 2012,2014), and it will be an interesting future study to compare the present results with a coupled experiment.

The domain included the North Pacific Ocean from $15^{\circ} \mathrm{S}$ to $72^{\circ} \mathrm{N}$ and from $99^{\circ} \mathrm{E}$ to $70^{\circ} \mathrm{W}$ (Fig. 3), at $0.1^{\circ} \times 0.1^{\circ}$ horizontal resolution and 41 vertical sigma levels with fine vertical mesh of $1-10 \mathrm{~m}$ near the surface. The model was forced by the cross-calibrated multiplatform wind (CCMP; Atlas et al. 2011) corrected near the eyewall by incorporating information such as maximum wind speed, minimum sea level pressure (SLP), and center location for Typhoon Nuri from the IBTrACS into the vortex model of Holland (1980). This was necessary as the CCMP wind underestimated the wind speed by as much as $50 \%$. The ocean model was run from 6 August to 25 August 2008 to cover the period of Nuri. Initial ocean fields on 6 August were estimated by assimilating satellite altimetry and SST data (e.g., Yin and Oey 2007), such that the Kuroshio, upper-ocean eddy variability, and SST 12 days prior to
Nuri could be more realistically represented. No data assimilation was used from 6 August to 25 August. The upperocean thermal fields were extensively validated against all available Argo (free-drifting profiling floats that measure the temperature and salinity of the upper $2000 \mathrm{~m}$ of the ocean; http://www-argo.ucsd.edu/) data during Nuri (see $\mathrm{SM})$. The regression between Argo and model was excellent: $T_{\mathrm{Argo}}=1.03 \times T_{\mathrm{POM}}-0.18$ with a high $R^{2}$ of 0.99 . The POM SST was then used in the WRF simulation (experiment 7 or pom_KS in Table 1). Additionally, by perturbing the various parameters in the ocean model simulation: IBTrACS track, minimum SLP, and radius of maximum wind, as well as the SST relaxation time constant and the interval of altimetry data assimilation during initialization, $\mathrm{POM}$ was repeated to produce a set of perturbed SSTs. These SSTs were then used to produce five additional WRF experiments (experiments 812 in Table 1). We emphasize that, although SST only was input into WRF, the POM SST dynamically reflected the complete upper-ocean structure before and throughout the lifetime of Nuri.

\section{Results}

\section{a. Comparison of modeled and observed tracks}

Simulated tracks are similar, insensitive to the different microphysics schemes and SSTs used (Fig. 4). They compare reasonably well with the observed tracks, except in the first 6-12 h probably because Nuri was then just a tropical storm with an unclear storm center and 
the model needed to adjust from imperfect initial conditions comprising of observations of possibly large uncertainty, as well as after 21 August when model tracks veered north before converging to the observed track at land fall. This supports the idea that a storm's track is primarily determined by the large-scale environment in which the tropical cyclone is embedded (Houze et al. 2007). The same large-scale wind from NCEP Operational Global Analysis data used for lateral boundary and initial conditions, therefore, resulted in similar biases for all the experiments.

\section{b. Observed intensity}

Figures $5 \mathrm{a}$ and $5 \mathrm{~b}$ plot the observed intensity as the minimum SLP and maximum wind speed averaged from values reported by different forecast centers in the IBTrACS dataset; the standard errors are also plotted. Nuri reached a maximum intensity at 0000 UTC 20 August when it entered the Luzon Strait. This maximum intensity divides the observed storm into two phases: an intensifying phase east of the Luzon Strait before 0000 UTC 20 August, and a weakening phase when the storm was in the South China Sea. From 18 to 19 August, the maximum wind speed (Fig. 5b) increased from 20 to $36 \mathrm{~m} \mathrm{~s}^{-1}$, which qualifies as a rapid intensification period according to Kaplan and DeMaria's (2003) definition of wind speed change exceeding $15.4 \mathrm{~m} \mathrm{~s}^{-1}(24 \mathrm{~h})^{-1}$. It is clear from Fig. 1a that the maximum intensity was reached immediately after (within $3 \mathrm{~h}$ ) Nuri crossed over the Kuroshio east of Luzon, and the drop in intensity thereafter coincided with the rapid thinning of the $Z_{26}$ from east $(\sim 100 \mathrm{~m})$ to west $(\sim 60 \mathrm{~m})$ across the Luzon Strait.

\section{c. Comparison of modeled and observed intensities}

Figure 5a compares the modeled intensity evolutions with observation. Model intensities on 18 August were weaker than observation because of initialization from the coarse-resolution global NCEP data; but from 18 to 19 August the modeled storms adjusted and all developed into typhoons. Such initial mismatch and the necessity for spinup because of initialization with coarse-resolution data have been previously noted (e.g., Braun and Tao 2000). Subsequent intensity evolutions of ncep_KS (red), ghr_KS (cyan), and pom_KS (blue) differ significantly.

\section{1) EXPERIMENT NCEP_KS}

The ncep_KS shows at 2100 UTC 19 August a local minimum of $964 \mathrm{hPa}$ (Fig. 5a), which is more than one standard deviation above the observed minimum. Moreover, unlike the observation, the simulated storm reintensified in the South China Sea to a peak intensity with SLP $=960 \mathrm{hPa}$ at 1500 UTC 21 August; the timing
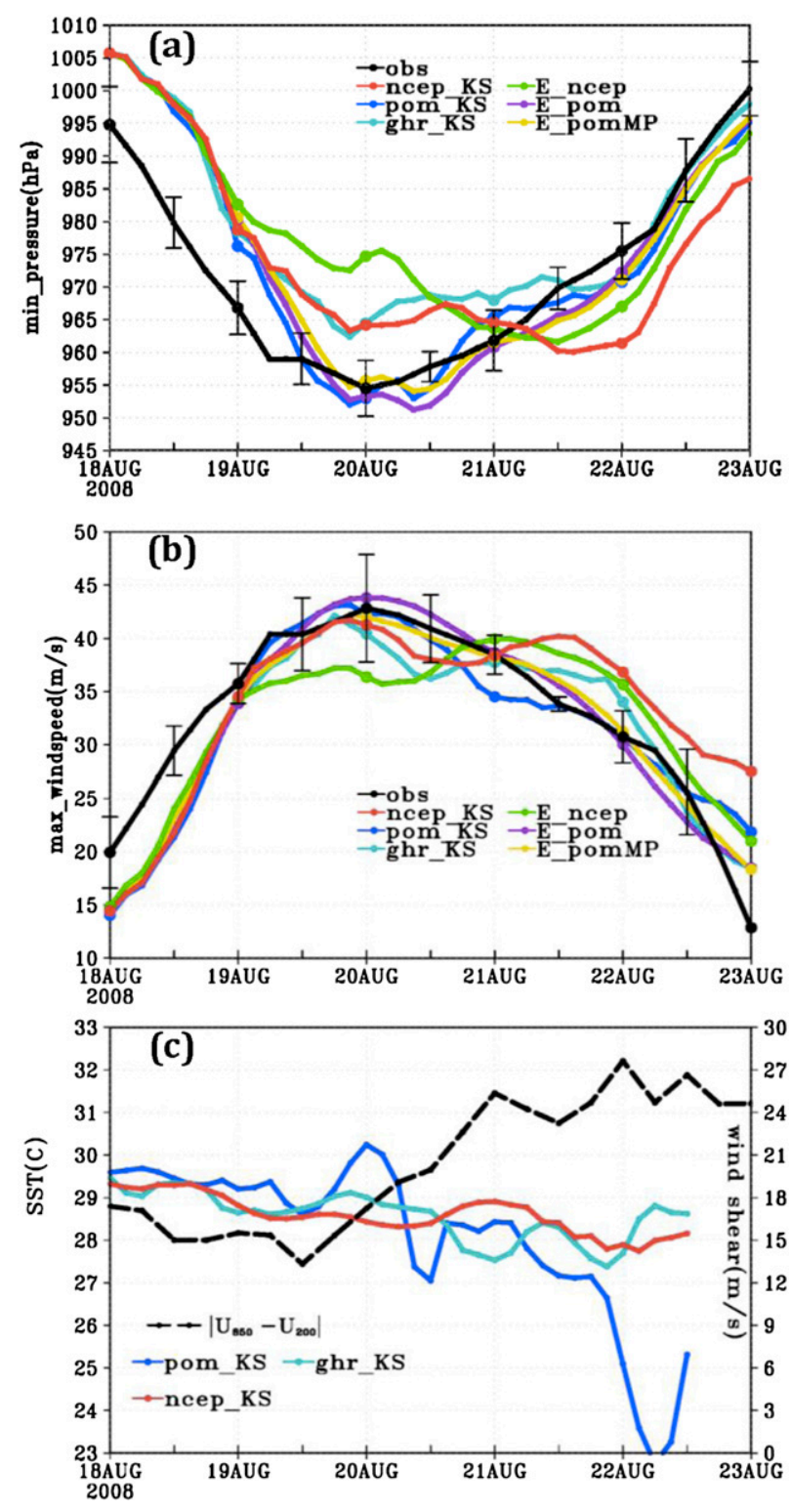

FIG. 5. Typhoon Nuri (a) minimum SLP from observations (black line), experiments (ncep_KS, pom_KS, and ghr_KS), and three ensembles (E_ncep, E_pom, and E_pomMP) during 18-23 Aug 2008. Vertical bars show standard errors of the minimum center pressure from the IBTrACS data. (b) As in (a), but for maximum 10-min sustained wind speed; the maximum 1-min sustained wind speed was $51 \mathrm{~m} \mathrm{~s}^{-1}$ (not shown) making Nuri a category 3 typhoon. (c) SSTs from ncep_KS, ghr_KS, and pom_KS averaged over a circular region with radius $50 \mathrm{~km}$ about the center of each modeled storm as it traversed across the ocean's surface during 18-23 Aug 2008. The black line shows environmental wind shear $=\left|\mathbf{U}_{850 \mathrm{hPa}}-\mathbf{U}_{200 \mathrm{hPa}}\right|$ calculated from the NCEP Operational Global Analysis data from a 200$800-\mathrm{km}$ radius from the observed storm center.

in the maximum intensity was therefore delayed by $39 \mathrm{~h}$ compared to the observation. Mismatches in the timing of maximum intensity appear to be quite common, and can be seen also in the results of other tropical cyclone 
models (e.g., Davis et al. 2008; Li and Pu 2008; Zhang et al. 2009; Green and Zhang 2013; Hendricks et al. 2013). The ncep_KS simulation continued to perform poorly throughout the weakening phase of the storm in the South China Sea: the modeled minimum center pressure was outside the range of the observed mean \pm 1 standard deviation. The behavior in term of maximum wind speed is similar (Fig. 5b). The reintensification to a stronger storm in the South China Sea existed in all the experiments using the NCEP SST [see the ensemble-averaged plot E_ncep (green) which shows a similar variation; also SM: Fig. SM6a]. Among the different microphysics schemes, the KS scheme yielded the fastest rate of intensification over the western Pacific, consistent with previous studies that single-phase schemes in general produced weaker downdrafts (Lord et al. 1984; Willoughby et al. 1984; Wang 2002; Li and Pu 2008; Tao et al. 2011). It also had the least RMS error and the least (false) reintensification in SCS (Fig. SM6b); the SBU-YLIN scheme had the largest error. Thus, while the modeled storms displayed some sensitivity, details in microphysics parameterization were not the determining factor that could explain the observed intensity change of Nuri.

\section{2) EXPERIMENT POM_KS}

In contrast to the ncep_KS, pom_KS did not reintensify in the South China Sea, and the intensity curve shows the same, observed strengthening and weakening phases before and after entering the South China Sea, although the maximum intensities occurred $3 \mathrm{~h}$ earlier at $2100 \mathrm{UTC}$ 19 August (Figs. 5a,b). There was a rapid intensification period from 1200 UTC 18 August to 1200 UTC 19 August during which the maximum wind speed increased from 22 to $42 \mathrm{~m} \mathrm{~s}^{-1}$, some $12 \mathrm{~h}$ later than observation. The minimum SLP of $952 \mathrm{hPa}$ agreed well with the observed minimum SLP of $954 \mathrm{hPa}$, and was within the standard error of the observation. The good agreement persisted in the South China Sea as Nuri weakened. The corresponding ensemble-averaged plots E_pom and E_pomMP (purple and gold) display similar variations of minimum SLP and maximum wind speed as the pom_KS experiment, showing that the results are robust to SST perturbations and different microphysics. The simulated Nuri showed a tendency to reintensify in the South China Sea when microphysics (experiments 13-16) other than KS scheme was used (not shown), but the peak intensity still occurred east of the Luzon Strait. The KS scheme again had the least RMS error, and experiments using the POM SST had smaller errors than those using the NCEP SST for all microphysics (Fig. SM6b). Since the two experiments were identical but for the SSTs, the results suggest that the SST had a significant influence in determining and improving the intensity change of Nuri.

\section{3) EXPERIMENT GHR_KS}

Experiment ghr_KS also did not reintensify in the South China Sea, but the simulated storm was too weak and the minimum SLP of $963 \mathrm{hPa}$ was more than one standard deviation above the observed minimum. After 0900 UTC 21 August, the intensity was similar to pom_KS.

\section{d. Effects of environmental wind shear on intensity}

The "wind shear" vector $\mathbf{V}_{s}=\mathbf{U}_{200 \mathrm{hPa}}-\mathbf{U}_{850 \mathrm{hPa}}$ (Fig. 4; Fig. 5c, black dashed line) was calculated as the difference in wind velocity between 200 and $850 \mathrm{hPa}$, spatially averaged within the annular region $200-800 \mathrm{~km}$ from the center of the storm at each instant (Chen et al. 2006). The climatological wind shear from June to October in the Philippine and South China Seas was eastnortheasterly and quite strong $\left|\mathbf{V}_{s}\right|>7.5 \mathrm{~m} \mathrm{~s}^{-1}$ [see Fig. 1b in Chen et al. (2006)]. Figure 4 shows that $\mathbf{V}_{s}$ during Nuri was similar to climatology, but stronger; the $\left|\mathbf{V}_{s}\right|$ exceeded $13 \mathrm{~m} \mathrm{~s}^{-1}$ throughout the life of the storm. The modeled shear agrees well with that observed for Nuri by Raymond and Carrillo (2011, see their Fig. 11). Previous studies found that strong shears $\left(\left|\mathbf{V}_{s}\right|>\sim 10 \mathrm{~m} \mathrm{~s}^{-1}\right)$ not only could prevent cyclogenesis but also weaken or even destroy a developed cyclone (DeMaria et al. 1993; DeMaria 1996; Frank and Ritchie 1999; Pielke and Landsea 1999; Goldenberg et al. 2001). Yet, as explained by Raymond and Carrillo (2011), despite the strong shear, Nuri rapidly intensified over western North Pacific. In the South China Sea, while the continuous weakening of both the observed and pom_KS intensities was consistent with increased $\left|\mathbf{V}_{s}\right|$, the ncep_KS reintensified in the South China Sea despite the same shear. These results suggest that while the environmental wind shear had some influence, it was not the main factor controlling the intensity change of Nuri.

\section{e. Influence of SST on intensity}

In pom_KS, the model storm rapidly intensified in the western North Pacific and reached a maximum intensity east of the Luzon Strait; it then rapidly decreased as the storm entered the South China Sea where the $Z_{26}$ dropped below $60 \mathrm{~m}$; these behaviors agree well with the observations (Fig. 5a).

The influence of SST can be understood by comparing the SSTs from ncep_KS, ghr_KS, and pom_KS (Fig. 5c). The along-track SST (Fig. 5 c) in pom_KS was consistently warmer than ncep_KS and ghr_KS in the western North Pacific. There was a warming of $1.5^{\circ} \mathrm{C}$ from 1200 UTC 19 August to 0000 UTC 20 August as Nuri continued to intensify to its peak during that period while crossing the Kuroshio, despite increasing wind shear. Then there was a rapid SST drop of about $3^{\circ} \mathrm{C}$ after the 
storm crossed the Kuroshio, from 0000 to 1200 UTC 20 August, and thereafter the storm weakened. Finally there was another precipitous drop of $4^{\circ}-5^{\circ} \mathrm{C}$ in the South China Sea as the storm continued to weaken. In contrast, SST changes in ncep_KS and ghr_KS were more gradual. The failure of NCEP SST to reproduce these dynamic changes in the ocean apparently resulted in the poor performances of the ncep_KS and E_ncep experiments. In particular, the warming over the Kuroshio was not seen in NCEP SST. For ghr_KS, there was a weak warming over the Kuroshio, from 0900 UTC 19 August to 2100 UTC 19 August, resulting in a weaker intensity than pom_KS.

Figure 6 compares storm-centric composites of SST and vertical velocity for ncep_KS, ghr_KS, and pom_ KS. While NCEP and GHR SSTs are smooth, the POM SST shows stronger contrast across the storm due to ocean dynamics (Sun et al. 2015; also below). The strongest updraft tends to be near the eyewall $50-60 \mathrm{~km}$ from the storm center, and also downshear left, which will be further discussed below. Most importantly, the pom_KS shows warmer (cooler) SST and stronger (weaker) $w$ than ncep_KS when Nuri was in the western North Pacific (South China Sea), while the SST and $w$ for ghr_KS are intermediate. As stronger updraft tends to be associated with a stronger storm (Riehl 1963; Emanuel 1986), and vice versa, these results are consistent with the intensity variations in Fig. 5.

Figures $7 \mathrm{a}-\mathrm{c}$ compare the three different SSTs at 0000 UTC 20 August before Nuri entered the South China Sea, as well as POM minus NCEP SST (Fig. 7d). All three products show generally cooler SSTs on the right side of the storm than on the left (Price 1981; Wentz et al. 2000; Oey et al. 2007; Huang and Oey 2015). However, whereas the cooling in POM SST was mostly behind and to the right of the storm (i.e., for times prior to 0000 UTC 20 August), the NCEP and GHRSST show unrealistic cooling extended ahead of the storm. Also, the POM SST showed a distinctively warmer SST along the Kuroshio, as well as some mesoscale features with large SST gradients in the South China Sea. There was cool SST over the shelf because of summertime coastal upwelling (Shu et al. 2011; Wang et al. 2012) by the southwesterly wind prior to the arrival of Nuri. The shelf SST = $27^{\circ}-29^{\circ} \mathrm{C}$ agrees well with the hydrographic data of Shu et al. (2011). By contrast, coastal upwelling, Kuroshio, and mesoscale features were absent in the NCEP and GHRSST products, which appeared smooth. Both NCEP and GHR SSTs are gridded products optimally interpolated from satellite data with some assumed scales both in space and time, which may include information prior to and after the time of interest. Our results show that they were unsuitable for simulating Typhoon Nuri.

\section{f. $Z_{26}$ and resonant inertial response}

The stark difference between POM SST and gridded products suggests a strong connection of SST to (storm induced) ocean dynamics. Figure 8 (shading) compares the SST change during Nuri for NCEP, GHRSST, and POM. The POM SST showed large spatial variability and cooling of $-3^{\circ}$ to $-6^{\circ} \mathrm{C}$ in the South China Sea, whereas both NCEP SST and GHRSST showed smooth and weaker cooling. The initial SST was approximately the same in the South China Sea and the western Pacific (Fig. 3), but a much stronger cooling occurred when Nuri was in the South China Sea after 0000 UTC 20 August compared to a modest SST decreases of $-1^{\circ} \mathrm{C}$ when the storm was east of the Philippines (red and blue contours, Fig. 8c). To explain, we note that the intensity curve in Fig. 5a is nearly symmetrical about 20 August when Nuri was over the Luzon Strait, so that the wind stresses were of similar magnitudes when Nuri was over the western Pacific and the South China Sea, and could not account for the large difference in SST due to different wind strengths. Therefore, the difference in cooling was mostly caused by different dynamical responses of the two basins. Details of the ocean response were analyzed and discussed in Sun et al. (2015); the most relevant results are described below.

First, the $Z_{26}$ was thinner in the South China Sea than in the western Pacific: $Z_{26 \mathrm{SCS}} / Z_{26 \mathrm{WP}} \approx 1 / 2$ (Fig. 1a; subscripts SCS and WP denote the South China Sea and the western Pacific, respectively). Oey et al. (2006) showed that, for the same wind power, cooling through vertical mixing and entrainment of cooler subsurface water tends to be greater where the $Z_{26}$ is thinner. By considering the change in temperatures due to mixing in a two-layer ocean with $Z_{26}$ overlying a much thicker lower layer, Sun et al. (2015) showed that

$$
\Delta T_{\mathrm{SCS}} / \Delta T_{\mathrm{WP}} \approx Z_{26 \mathrm{WP}} / Z_{26 \mathrm{SCS}} \approx 2,
$$

where $\Delta T=$ change in SST (after the storm minus before). Since $\Delta T_{\mathrm{WP}} \approx-1^{\circ} \mathrm{C}$ (Fig. 8c), this mechanism would contribute to an estimated cooling in the South China Sea $\Delta T_{\mathrm{SCS}}$ of about $-2^{\circ} \mathrm{C}$.

Second, inertial currents $\left(\mathbf{u}_{I}\right)$ were produced by the passage of Nuri. Inertial currents generate shears, hence, turbulence and mixing both in the surface layer of the ocean, as well as subsurface as internal waves, often as "chimneys" of near-inertial internal waves (Kunze 1985; Lueck and Osborn 1986; Kunze et al. 1995; Oey et al. 2008). Figure 9a shows contours of inertial amplitude $\left|\mathbf{u}_{I}\right|$ at the surface, computed following Wang and Oey (2008), superimposed on the $Z_{26}$ (color shading). The inertial amplitude became large in the Luzon Strait and when the storm was in the South China Sea where $\left|\mathbf{u}_{I}\right|$ exceeded $1.5 \mathrm{~m} \mathrm{~s}^{-1}$ along the path of the storm, while 

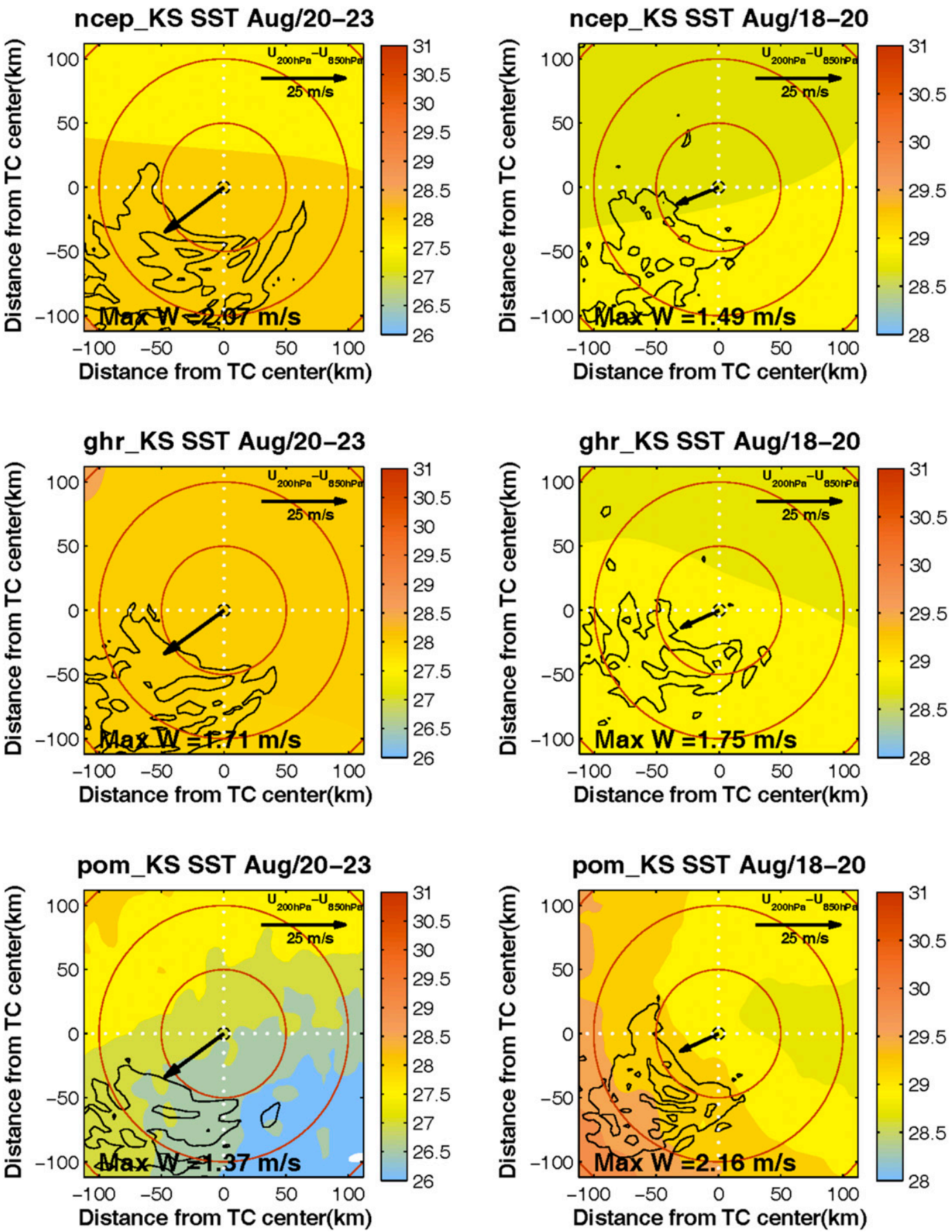

FIG. 6. Storm-centric composites of SST (shading, ${ }^{\circ} \mathrm{C}$ ) and $w$ (contours $0.6,1.2,1.8, \ldots \mathrm{m} \mathrm{s}^{-1} ; 850-200 \mathrm{hP}$ averaged) during the (right) intensifying (western North Pacific) and (left) weakening (South China Sea) phases of Typhoon Nuri, for (top) ncep_KS, (middle) ghr_KS, and (bottom) pom_KS. Max $w$ is displayed at the bottom. The domain is $100 \mathrm{~km} \times$ $100 \mathrm{~km}$. The mean wind shear vector is shown at the typhoon's center with the scale shown at the top right, and concentric circles were drawn with $50-$ and $100-\mathrm{km}$ radii.

values were weaker, $\left|\mathbf{u}_{I}\right| \approx 0.9 \mathrm{~m} \mathrm{~s}^{-1}$ in the western Pacific. The along-track inertial amplitude (blue line in Fig. 9b) increases from the western Pacific to the South China Sea. The along-track Richardson number
$\mathrm{Ri}_{o}=-\left(g / \rho_{b o}\right)\left(\partial \rho_{o} / \partial z\right) /\left[\left(\partial u_{o} / \partial z\right)^{2}+\left(\partial v_{o} / \partial z\right)^{2}\right]$ (subscripts $o$ denote ocean and $b$ background; red line) is anticorrelated with the inertial amplitude showing the dominance of the vertical shears due to inertial currents in controlling $\mathrm{Ri}_{o}$. 
(a)

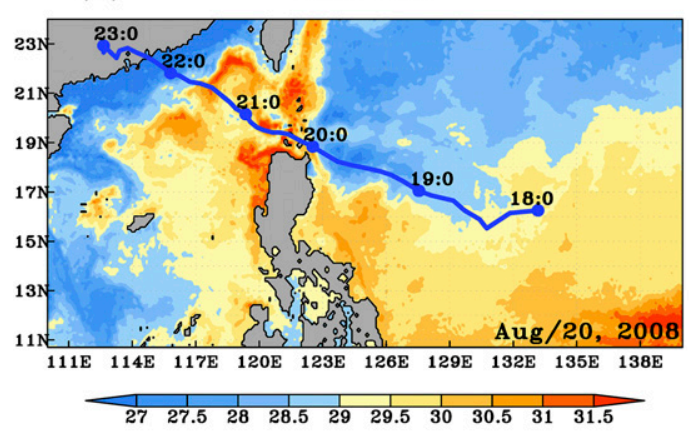

(c)

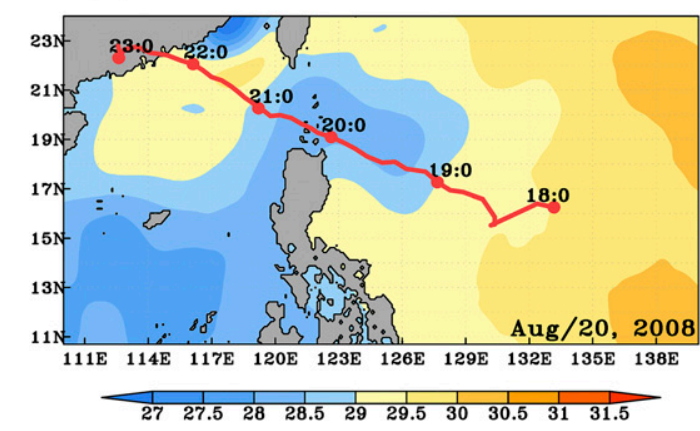

(b)

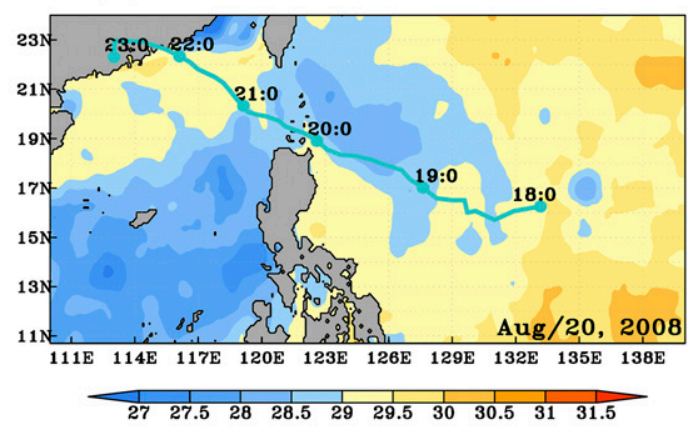

(d) POM-NCEP SST

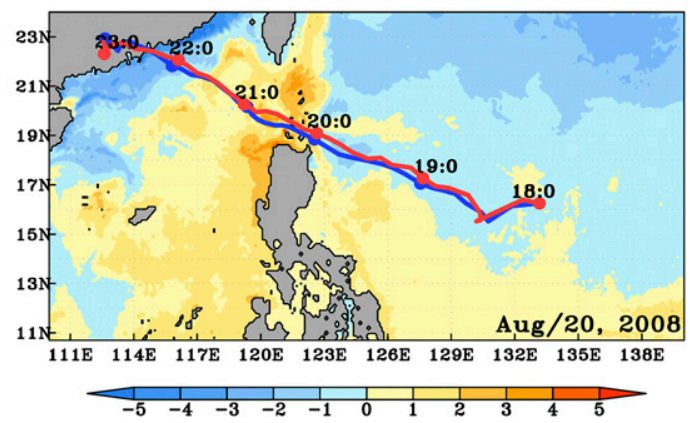

FIG. 7. Sea surface temperatures (SST in ${ }^{\circ} \mathrm{C}$ ) at 0000 UTC 20 Aug 2008 from (a) POM, (b) GHRSST, and (c) NCEP. (d) POM minus NCEP SST. Lines with daily markers show the simulated tracks using the same colors as those for the minimum SLP plot in Fig. 5.

The resulting increased turbulence in the South China Sea is shown by the along-track eddy diffusivity (black line) that on average was larger during the 2 days after 20 August than before. The rightward cooling bias is clearly seen in Fig. 9a, because the wind vector rotates in rough resonance with the inertial current vector (Price 1981; Wang and Oey 2008). Exact resonance occurs when the forcing frequency of the passing storm, $\omega_{F}=2 \pi U / L$ is equal to the Coriolis frequency $f$, where $U$ is the translation speed and $L$ is twice the radius of influence of the storm. If this radius is taken to be where the storm's wind speed has fallen below $18 \mathrm{~m} \mathrm{~s}^{-1}$ (black contour in Fig. 1a), the minimum speed assigned for a tropical storm (Landsea 2000), then for Nuri the inertial response was in resonance in the South China Sea (Table 2). In contrast, in the western Pacific, a combination of lower latitude $\left(17^{\circ} \mathrm{N}\right)$ and faster $U\left(7 \mathrm{~m} \mathrm{~s}^{-1}\right)$ resulted in nonresonance $f \neq \omega_{F}$ (Table 2), hence, a weaker $\left|\mathbf{u}_{I}\right|{ }^{1}$ Sun et al.

\footnotetext{
${ }^{1}$ The $L$ here corresponds to $8 \times R_{\max }$ used by Price et al. (1994) in terms of the radius of maximum wind speed $R_{\max }$, which is about $60 \mathrm{~km}$ for Typhoon Nuri (see below). There is some arbitrariness in the choice of $18 \mathrm{~m} \mathrm{~s}^{-1}$ as the minimum speed that determines the radius of influence of the tropical cyclone. A choice of $L \approx 1000 \mathrm{~km}$ would give resonance in the western Pacific but the scale is unreasonably large in view of the observations.
}

(2015) showed that the resonance mechanism largely contributed to the remaining stronger cooling of about $-1^{\circ}$ to $-4^{\circ} \mathrm{C}$ in the South China Sea (Fig. 8c).

\section{g. Observed and modeled precipitations}

Figures 10a and 10b compare the observed and modeled rain-rate composites during Nuri. The observation is from the high-resolution Tropical Rainfall Measuring Mission (TRMM) product (http://daac.gsfc. nasa.gov), and the model is pom_KS (ncep_KS and other experiments show a similar pattern). The observed and modeled averaged rain rates are $\approx 4.1$ and $6.4 \mathrm{~mm} \mathrm{~h}^{-1}$, respectively. Sensitivity of modeled precipitation to convective parameterizations, microphysics, and boundary layer schemes have been reported in the literature (e.g., Wang and Seaman 1997). Efstathiou et al. (2013), Marteau et al. (2015), and Pennelly et al. (2014) found that WRF tended to overestimate the amount of rainfall. The observation also shows a more widespread rain pattern while the model is more concentrated near the center (Figs. 10a,b). On the other hand, good agreements in the asymmetry of the rain pattern can be seen: observation and model both show southward biases. From composite analyses of the TRMM data, Chen et al. (2006) showed that vertical wind shear and storm 
(a)

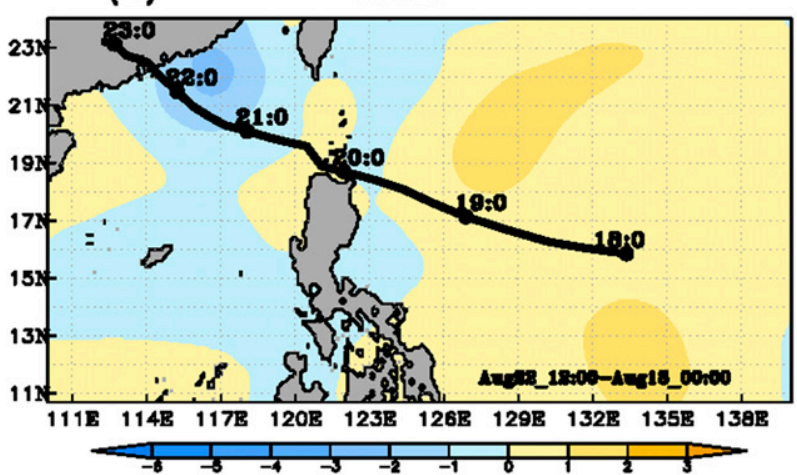

(b)

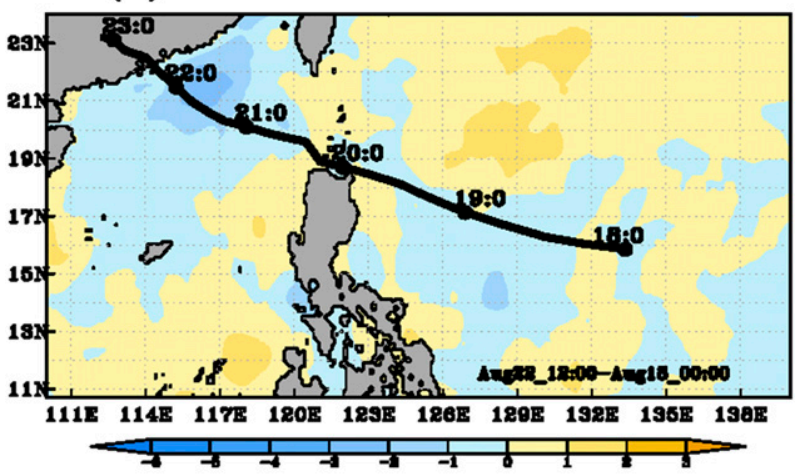

(c)

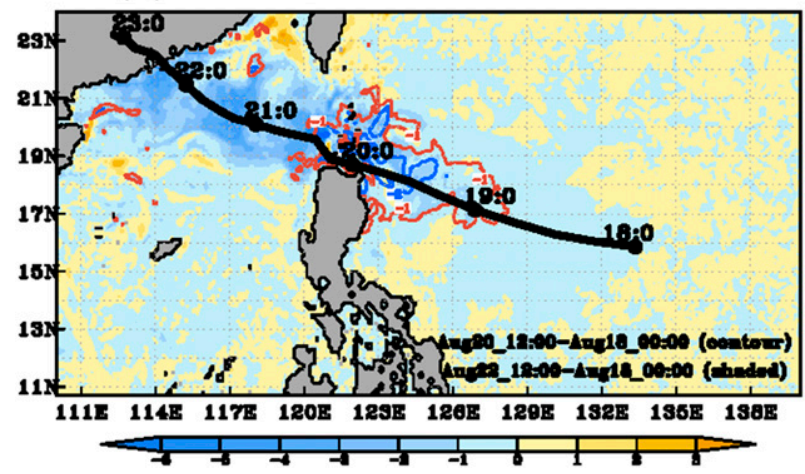

FIG. 8. SST change (shading; ${ }^{\circ} \mathrm{C}$ ) defined as SST at end of Nuri (1200 UTC 22 Aug) minus SST at the beginning (0000 UTC 18 Aug) for (a) NCEP, (b) GHRSST, and (c) POM. The observed Typhoon Nuri track from IBTrACS is plotted with daily positions shown as dots. Contours $\left[-1^{\circ}\right.$ (red) and $-2^{\circ} \mathrm{C}$ (blue) $]$ in (c) are SST at 1200 UTC 20 Aug minus SST at 0000 UTC 18 Aug (see text).

translation were two of the most important factors contributing to rainfall asymmetries in tropical cyclones. The vertical wind shear tended to dominate when shear is $>5 \mathrm{~m} \mathrm{~s}^{-1}$, and the rainfall asymmetry was predominantly downshear left for shear values $>7.5 \mathrm{~m} \mathrm{~s}^{-1}$. These conditions were satisfied during Nuri, for which the averaged wind shear exceeded $12 \mathrm{~m} \mathrm{~s}^{-1}$ (see Figs. 4 and 5c),
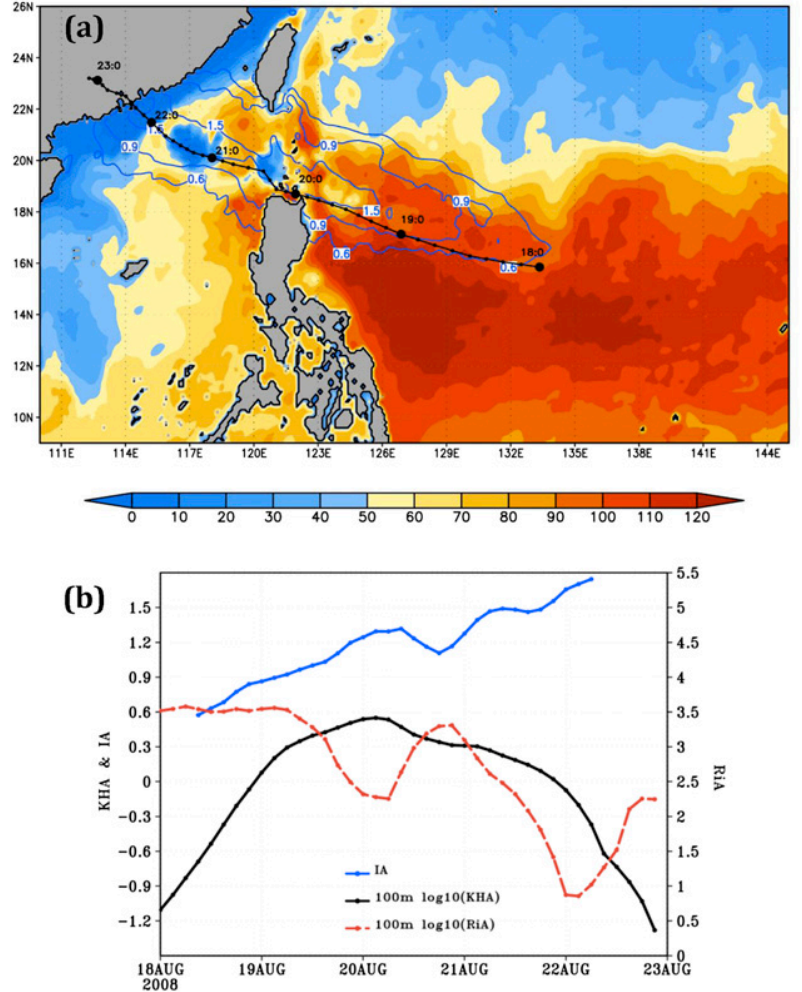

FIG. 9. (a) Amplitude of near-inertial current $\left|\mathbf{u}_{I}\right|$ (contours in $\mathrm{m} \mathrm{s}^{-1}$ ) at the first (i.e., surface) grid point of POM. Color shading is the depth of $26^{\circ} \mathrm{C}$ isotherm, $Z_{26}(\mathrm{~m})$, at 0000 UTC 22 Aug 2008. The observed Typhoon Nuri track from IBTrACS is plotted with daily positions shown as dots. (b) Along-track inertial amplitude $(\mathrm{IA})=\left|\mathbf{u}_{I}\right|$ averaged inside a circle of $50-\mathrm{km}$ radius from the typhoon center (blue), and $\log _{10}$ of eddy diffusivity (KHA; black) and Richardson number (RIA; red) averaged from the surface to $100 \mathrm{~m}$ below and inside the same circle of $50-\mathrm{km}$ radius from the typhoon center.

and the rain-rate patterns were strongly asymmetric to the left of the downwind side of the shear (Figs. 10a,b).

It is well known that a tropical cyclone in a vertical wind sheared environment would develop upward motion on the downwind side of the shear (Raymond 1992; Jones 1995). A process model study by Wang and Holland (1996) showed that convective asymmetries developed with enhancement downshear left. Figure 10c plots the vertical velocity composite (shading) and shows clearly the downshear-left enhancement. In the model, the maximum precipitation pattern was downwind of the cyclonic wind of the storm (contours in Fig. 10c). Zhang and Kieu (2005) pointed out that in an axisymmetric cyclone assuming quasigeostrophy without heating and friction, the $\omega$ equation (Holton 2004) would yield a vertical motion in the presence of vertical wind shear. The recirculating vertical cell then developed in the wind shear vertical plane across the storm's inner core, 
TABLE 2. Parameters related to typhoon Nuri when it was in the South China Sea and the western North Pacific east of the Philippines: $f=$ Coriolis frequency, $L=$ influence diameter of the typhoon, $U=$ translational speed of the typhoon, $\omega_{F}=$ forcing frequency of wind at a fixed point as the typhoon passes, and $\mathbf{u}_{I}=$ near-inertial velocity.

\begin{tabular}{lcc}
\hline \hline Parameters & $\begin{array}{c}\text { South China Sea } \\
\left(\text { Nuri at } 20^{\circ} \mathrm{N}\right)\end{array}$ & $\begin{array}{c}\text { Western Pacific } \\
\left(\text { Nuri at } 17^{\circ} \mathrm{N}\right)\end{array}$ \\
\hline$f\left(\mathrm{~s}^{-1}\right)$ & $5 \times 10^{-5}$ & $4 \times 10^{-5}$ \\
$L(\mathrm{~km})$ & 550 & 550 \\
$U\left(\mathrm{~m} \mathrm{~s}^{-1}\right)$ & 5 & 7 \\
$\omega_{F}=2 \pi U / L$ & $5.5 \times 10^{-5}$ & $7.7 \times 10^{-5}$ \\
$\left|\mathbf{u}_{I}\right|\left(\mathrm{m} \mathrm{s}^{-1}\right)$ & $>1.5$ & 1 \\
\hline
\end{tabular}

with rising motion downshear, descending air behind, and a vertically sheared cross-plane flow opposing the environmental wind shear. We calculated the pattern of the vertical velocity from the $\omega$ equation:

$$
w_{\omega} \approx C f_{o}\left(\partial \mathbf{u}_{g} / \partial p \cdot \nabla \zeta_{a}\right)
$$

(Fig. 10d), which can be compared with the modeled $w$ field of Fig. 10f. Here, $w_{\omega}$ is in meters per second, $f_{o}$ is the constant Coriolis parameter, $\mathbf{u}_{g}$ is the geostrophic wind, $p$ is pressure, $\zeta_{a}=f+\mathbf{k} \cdot \nabla \times \mathbf{u}_{g}$ is the vertical component of the absolute vorticity, $\mathbf{k}$ is the unit vector in the vertical $z$ direction, and $C$ is a multiplicative factor that is $\approx 1.44 \times 10^{14}$ based on a length scale of $60 \mathrm{~km}$ in the vicinity of the eye of Nuri in its matured phase. The $w_{\omega}$ shows upwelling downshear and downwelling upshear in agreement with Zhang and Kieu (2005); however, a large area of upwelling is seen to the right of the shear. With diabatic heating, Wang and Holland (1996) showed that the positive PV produced in the lower troposphere inside the eyewall (see the next section) developed a cyclonic rotation until the enhanced upwelling was downshear left (see their Fig. 9a). In the $\omega$ equation, the effects of the PV production can be approximately diagnosed by replacing the $\mathbf{u}_{g}$ by the modeled wind. The resulting vertical velocity field is shown in Fig. 10e; generally good agreement with the actual $w$ field from the model (Fig. 10f) can be seen.

\section{Intensification of Typhoon Nuri: A positive feedback mechanism}

We saw above that Nuri rapidly intensified over the western North Pacific (18-20 August 2008). Our goal here is to explain the process by drawing from the works of previous researchers and condensing the ideas into a unified framework (Fig. 15 below). We focus on experiment pom_KS as it could more realistically simulate the observed intensity change, and it will be compared against ncep_KS to further understand the influence of SST.
The Ertel (1942) [see Schubert et al. (2004) for the English translation] PV and PV-tendency equations are as follows (Stoelinga 1996):

$$
\begin{aligned}
q & =\frac{1}{\rho} \boldsymbol{\eta}_{a} \cdot \nabla \theta, \\
\frac{d q}{d t} & =\frac{1}{\rho}\left(\boldsymbol{\eta}_{a} \cdot \nabla \dot{\theta}+\nabla \times \mathbf{F} \cdot \nabla \theta\right) .
\end{aligned}
$$

Here $q$ is PV, $\rho$ is the dry-air density, $\boldsymbol{\eta}_{a}=\left(\xi_{a}, \eta_{a}, \zeta_{a}\right)$ is the three-dimensional absolute vorticity vector, $\theta$ is the potential temperature, $\dot{\theta}$ is the Lagrangian heating rate (henceforth, heating tendency), $\nabla$ is the three-dimensional gradient operator, $\mathbf{F}=\partial\left(K_{M} \partial \mathbf{u} / \partial z\right) / \partial z$ is the threedimensional frictional acceleration, $K_{M}$ is the exchange coefficient for momentum, and $\mathbf{u}$ is the wind velocity. In the derivation of (4.2) (e.g., Pedlosky 1982), a solenoidal term $\rho^{-3} \nabla \theta \cdot(\nabla \rho \times \nabla p)$ on the rhs vanishes, since $\theta$ is a function of $\rho$ and $p$ only. Schubert et al. (2001) showed that (4.1) and (4.2) are valid also for a moist atmosphere but using the virtual potential temperature instead of $\theta$, and using total density, which includes the mass density of airborne moisture and precipitating water substance. ${ }^{2}$ Hausman et al. (2006) confirmed the approximate validity of using (4.1) and (4.2) in their model analyses. In plots to be presented below, virtual potential temperature and total density were used using the same notations $(\theta, \rho)$; the results were not significantly different if their dry counterparts were used.

The friction can be approximated by $\mathbf{F} \approx-C_{f} \mathbf{u}_{s}$, where $\mathbf{u}_{s}$ is the near-surface wind and $C_{f}$ is a friction coefficient with the unit of per second. Approximate the horizontal portion of $\nabla \theta$ in (4.2) by thermal wind, $\nabla_{H} \theta \approx-[f /(\alpha g)] \mathbf{k} \times\left(\partial \mathbf{u}_{g} / \partial z\right)$, where $\nabla_{H}$ is the horizontal gradient operator, $\alpha$ is the thermal expansion coefficient, $g$ is the acceleration due to gravity, and $\mathbf{u}_{g}$ is the geostrophic velocity, (4.2) becomes

$$
\begin{aligned}
\frac{d q}{d t} \approx & \frac{1}{\rho}\left[\boldsymbol{\eta}_{a} \cdot \nabla \dot{\theta}+\left(\frac{C_{f} f}{\alpha g}\right)\left(\nabla \times \mathbf{u}_{s}\right) \cdot\left(\mathbf{k} \times \frac{\partial \mathbf{u}_{g}}{\partial z}\right)\right. \\
& \left.-C_{f} \mathbf{k} \cdot \nabla \times \mathbf{u}_{s} \frac{\partial \theta}{\partial z}\right] .
\end{aligned}
$$

From (4.2), positive PV is produced by the gradient of diabatic heating in the direction of $\boldsymbol{\eta}_{a}$. It is also produced by frictionally generated vorticity vector pointing in the same direction as $\nabla \theta$ or, approximately by surface wind

\footnotetext{
${ }^{2}$ As shown in Schubert et al. (2001), there is an extra PVproduction term on the rhs of (4.2) due to the mass divergence of the precipitating water substance, which, however, is generally small; see also Hausman et al. (2006).
} 
TRMM Rainrate

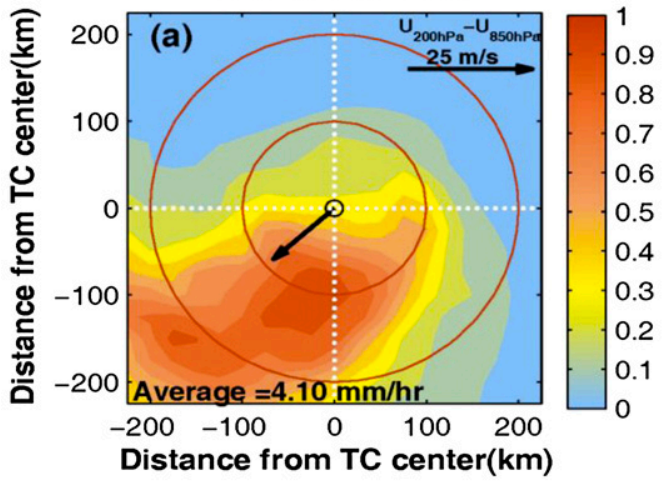

pom_KS Rainrate

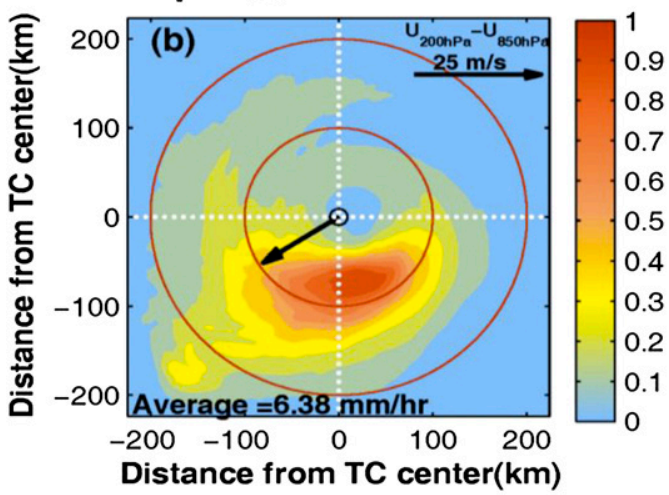

pom_KS w

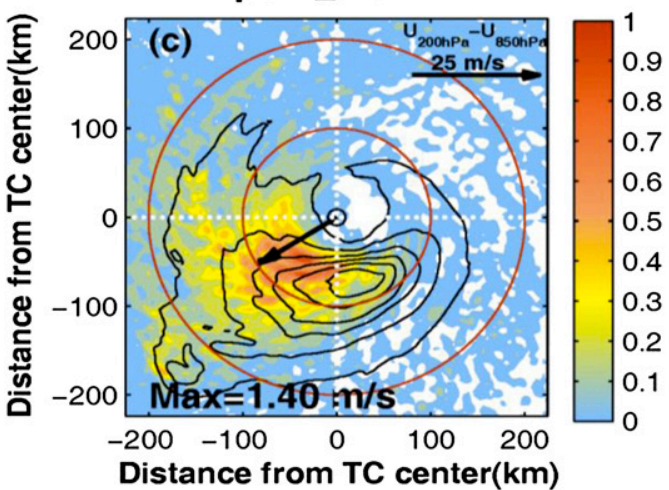

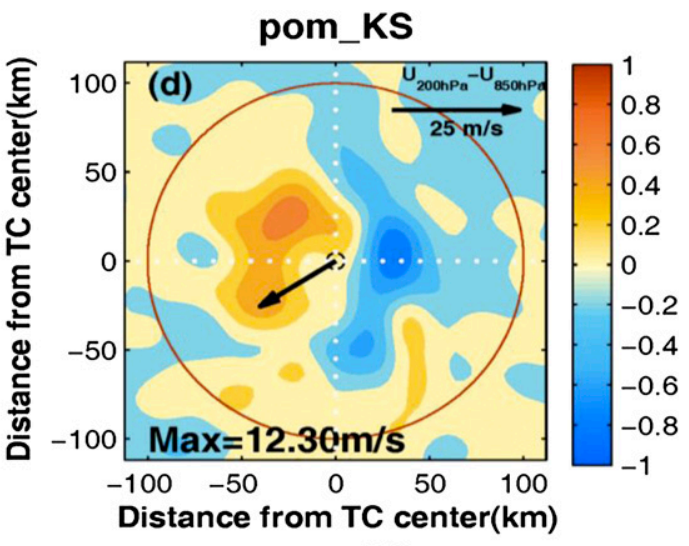

pom_KS
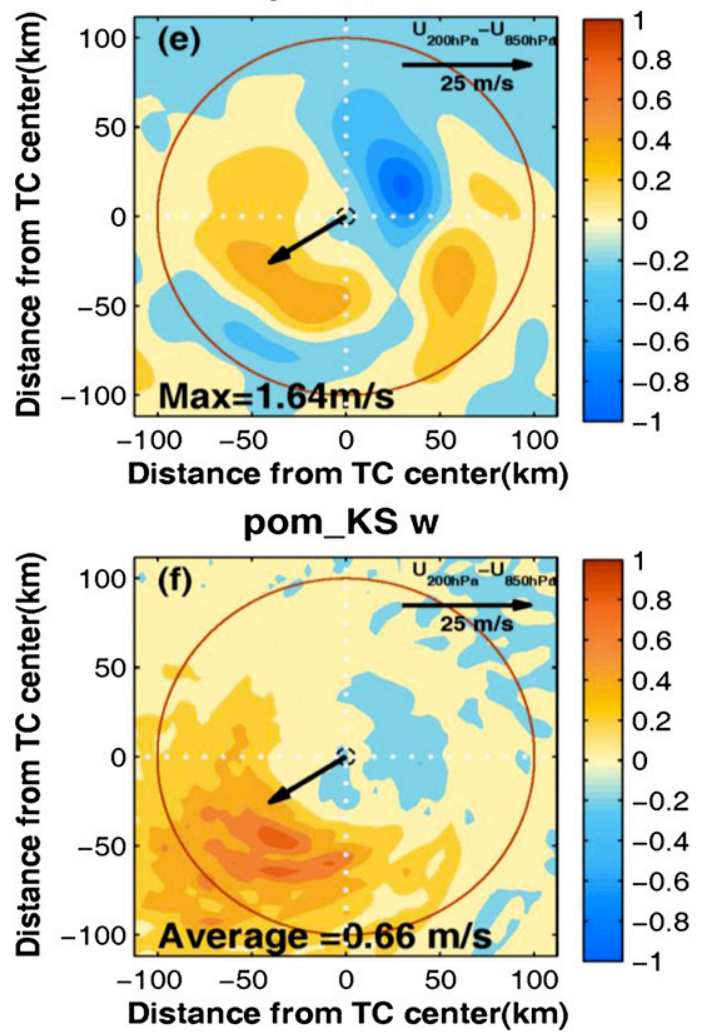

FIG. 10. The 18-23 Aug composites of rain rates from (a) TRMM and (b) pom_KS, and of (c) pom_KS $w$ with contours of rain rate [as in (b)], (d),(e) $w$ from the $\omega$ equation but in (e) geostrophic shear is replaced by model wind shear (see text), and (f) $w$ [as in (c)] to compare with (e). Domain is $200 \mathrm{~km} \times 200 \mathrm{~km}$ in (a)-(c) and is $100 \mathrm{~km} \times$ $100 \mathrm{~km}$ in (d)-(f). Mean wind shear vector is shown at the typhoon's center with scale shown at top right, and concentric circles show $100-$ and $200-\mathrm{km}$ radii in (a)-(c) and $100-\mathrm{km}$ radii in (d)-(f). All plots are normalized by respective maximum values. The $w$ in (c)-(f) are averaged from 850 to $200 \mathrm{hPa}$. Averages or maxima of shaded variables are displayed along the bottom.

$\left(\mathbf{u}_{s}\right)$ that points in the opposite direction as the thermal wind $\left(\partial \mathbf{u}_{g} / \partial z\right)$ from $(4.3)$; in a tropical cyclone, $\mathbf{u}_{s}$ opposes $\left(\partial \mathbf{u}_{g} / \partial z\right)$, and friction tends to produce PV. Stoelinga (1996) showed that latent heat of condensation produced positive PV in the lower troposphere (below $800 \mathrm{hPa}$ ) and was the dominant contributor to the strengthening of a rapidly intensifying cyclone that the author analyzed; the frictional contribution was smaller but positive near the center of the cyclone.

Figure 11 compares the $\dot{\theta}$ and $1 / \rho\left(\boldsymbol{\eta}_{a} \cdot \nabla \dot{\theta}\right)$ from the pom_KS and ncep_KS experiments, showing large contribution of PV tendency to the left of the heating. In 

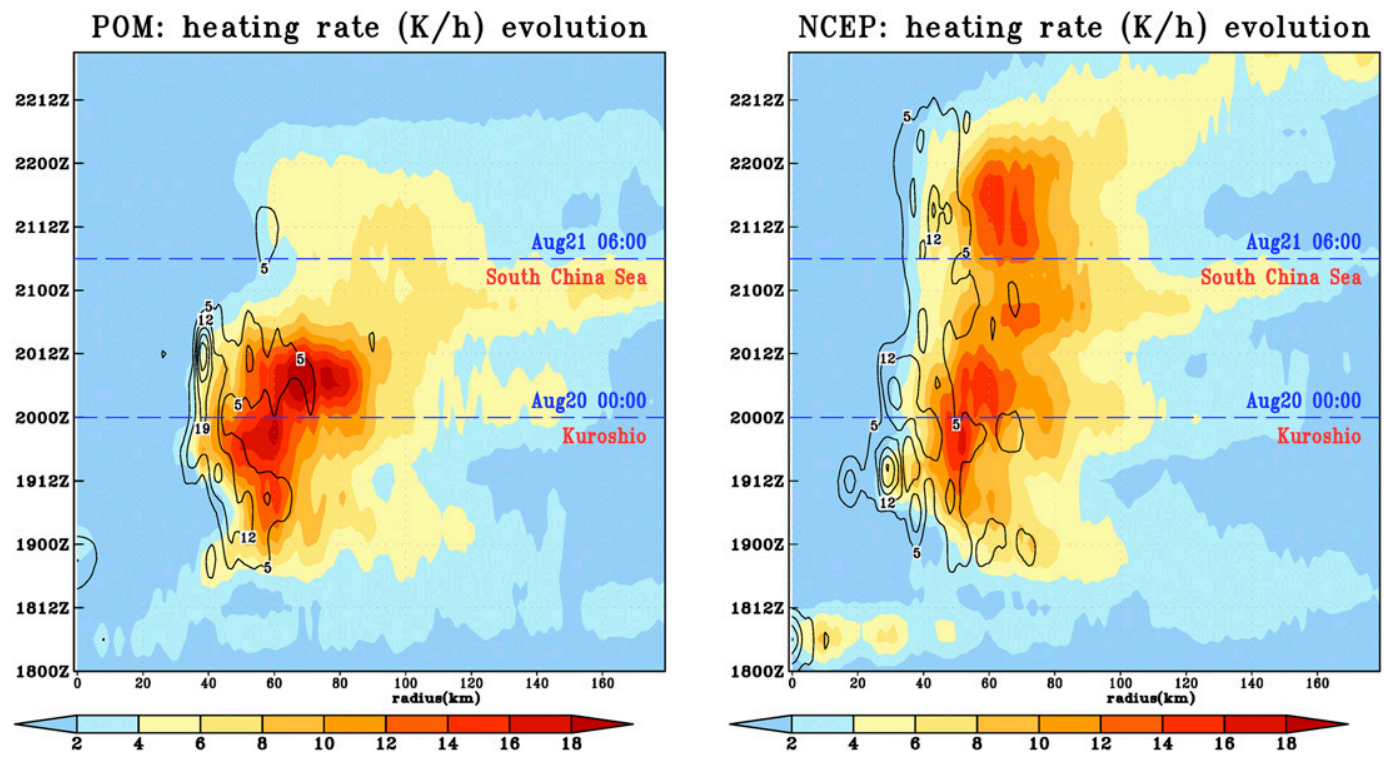

FIG. 11. Azimuthally averaged $\dot{\theta}$ (color shading layer-averaged $975-200 \mathrm{hPa}$ ) in $\mathrm{K} \mathrm{h}^{-1}$, and diabatic contribution to PV tendency (contours, in PVU h ${ }^{-1} ; 1 \mathrm{PV}$ unit $=10^{-6} \mathrm{~K} \mathrm{~kg}^{-1} \mathrm{~m}^{2} \mathrm{~s}^{-1}$, layer averaged from 975 to $850 \mathrm{hPa}$ ), for (left) pom_KS and (right) ncep_KS experiments, plotted as a function of time. For reference, dotted lines show times when Typhoon Nuri was over the Kuroshio and the South China Sea.

both experiments, there were strong heating and large positive tendencies when Nuri was over the Kuroshio around 20 August, and the values in pom_KS were larger. In ncep_KS, there were additional heating and PV tendency around 1200 UTC 21 August when the model typhoon was in the South China Sea; this corresponds to the (erroneous) reintensification of the storm described previously (Figs. 5a,b).

We now describe how the intensification of Nuri can be explained in terms of coupled reinforcements of PV production, outward leaning of the $\boldsymbol{\eta}_{a}$ vector and radial inflow. We examine azimuthally averaged variables in the radial-height plane at three times: 0300, 1200, and 2100 UTC 19 August during the storm's intensification phase (Fig. 12). In the followings, we refer to the radial coordinate as $r$ or $x$ with velocity component $u$ and the height coordinate as $z$ with velocity component $w$; the azimuthal coordinate is $y$ with velocity component $v$. At the early stage, condensation produces localized heating tendencies in the lower troposphere, clustering near the nascent eyewall where the mixing ratio is higher (near $r \approx 50 \mathrm{~km}$ ) (Fig. $12 \mathrm{c}$ at 0300 UTC 19 August green contours, and Fig. 12d); this favors the production of positive PV below left of the heating where the gradient of heating in the direction of $\boldsymbol{\eta}_{a}$ is positive [i.e., near the surface in the core of the storm; Fig. 12c color shading; Stoelinga (1996)]. Since before the storm the vectors $\boldsymbol{\eta}_{a}$ and $\nabla \theta$ initially point upward, $q$ cannot increase by the change in the angle between them but must be due to increased $\left|\boldsymbol{\eta}_{a}\right|=\left(\xi_{a}^{2}+\zeta_{a}^{2}\right)^{1 / 2}$ or $|\nabla \theta|$, or both. As the storm intensifies from 0300 to 1200 UTC 19 August (Fig. 12b, black $v$ contours), Fig. 12a shows that both $\xi_{a}$ and $\zeta_{a}$ increase though $\xi_{a}$ increases more rapidly, resulting in the outward leaning of the $\boldsymbol{\eta}_{a}$ vector; the magnitude of the absolute vorticity agrees well with that measured by Raymond and Carrillo (2011, see their Fig. 8). The $\theta$ contours rotate anticlockwise with height and become tighter (Fig. 12c, black contours). At the same time, radial inflow within the PBL strengthens (Fig. 12b, shading and vectors). To understand the connection between these different processes, consider first surfaces of the absolute angular momentum per unit mass:

$$
\Omega=v r+f r^{2} / 2,
$$

which are plotted in Fig. 12c (blue contours). In terms of $\Omega$, the azimuthal momentum equation is

$d \Omega / d t \equiv r d v / d t+v u+r f u=-\rho^{-1} \partial p / \partial \phi+r F^{y}$,

where $\phi=r^{-1} d y$ is the azimuthal angle, $d / d t \equiv \partial / \partial t+$ $u \partial / \partial r+(v / r) \partial / \partial \phi+w \partial / \partial z$, and $F^{y}$ is the azimuthal component of the frictional acceleration $\mathbf{F}$. Then, for a symmetrical vortex (which in our case is approximated by azimuthal averaging),

$$
d \Omega / d t \approx 0
$$



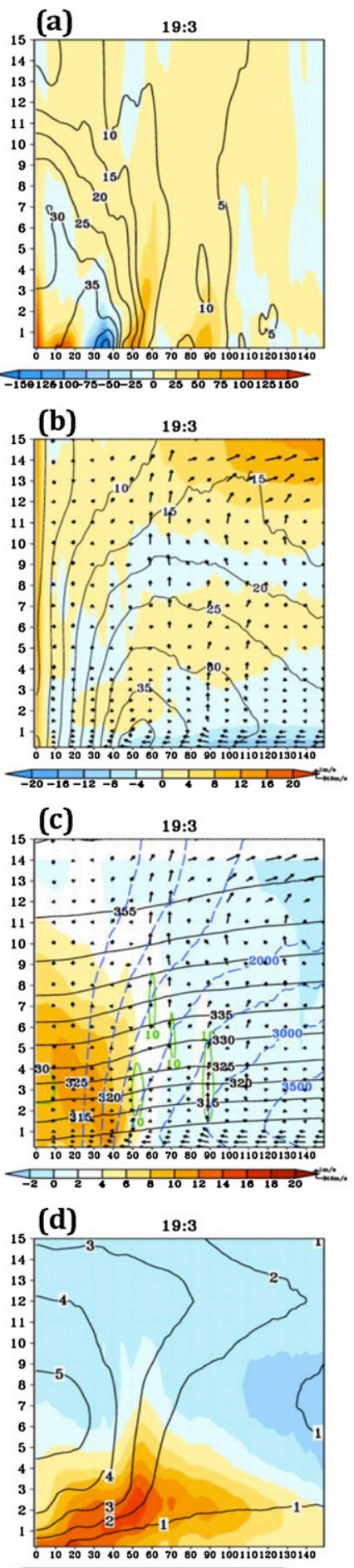

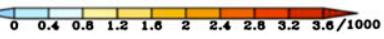
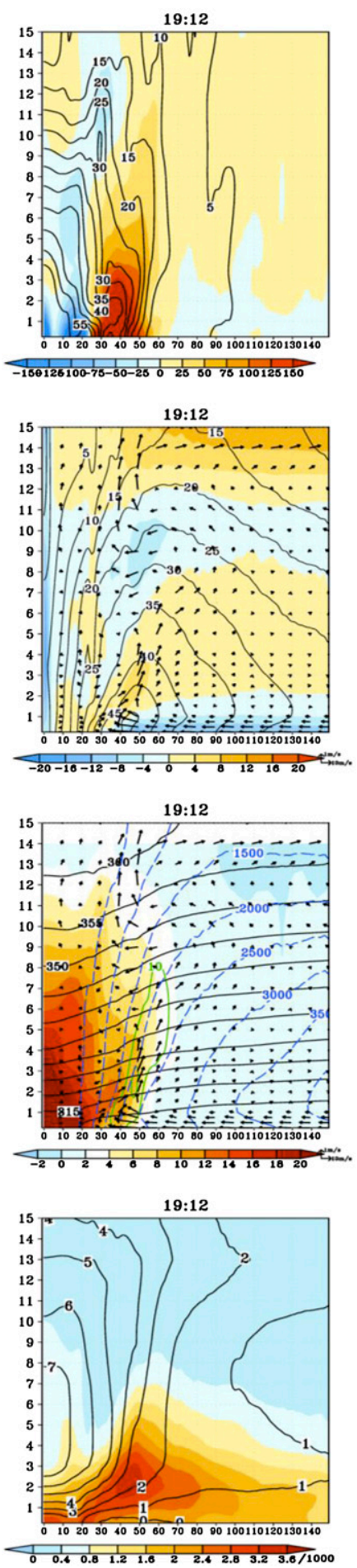
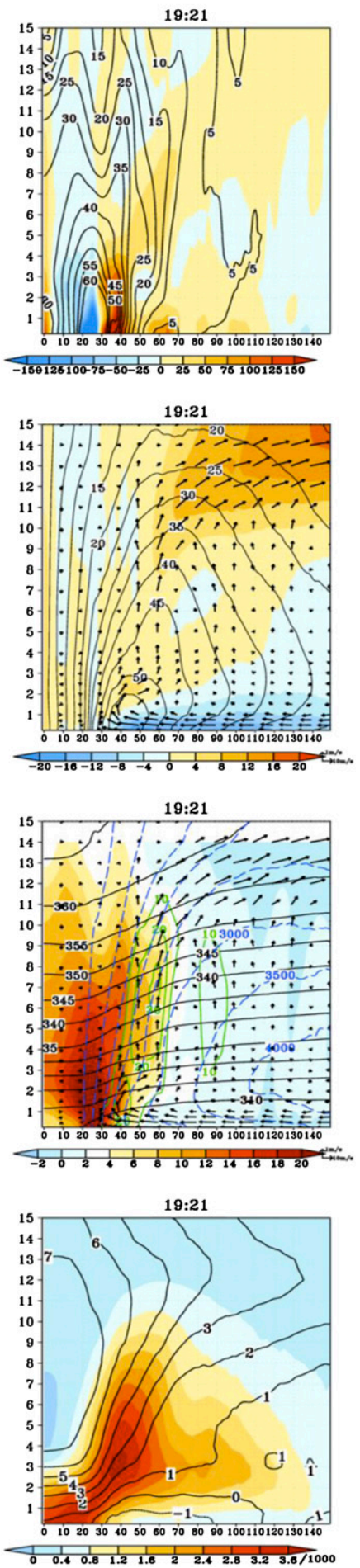

FIG. 12. (a) Radial (abscissa, $\mathrm{km}$ ) and height (ordinate, $\mathrm{km}$ ) plots of the azimuthally averaged $\left(\xi_{a}, \zeta_{a}\right) / f($ color shading and contours). (b) The $(u, v)$ (color shading and contours, $\mathrm{m} \mathrm{s}^{-1}$ ) and $(u, w)$ vectors in $\mathrm{m} \mathrm{s}^{-1}$ (reference vectors on bottom right). (c) PV anomaly (=PV minus background PV $f \partial \theta_{\mathrm{bg}} / \partial z$, color shading PVU; $1 \mathrm{PV}$ unit $=$ $10^{-6} \mathrm{~K} \mathrm{~kg}^{-1} \mathrm{~m}^{2} \mathrm{~s}^{-1}$ ) based on the virtual potential temperature $\theta_{v}$ (black contours $\mathrm{K}$ ), blue contours are $\Omega$ $\left(\times 10^{3} \mathrm{~m}^{2} \mathrm{~s}^{-1}\right)$ and green contours are heating tendency $\dot{\theta}\left(\mathrm{K} \mathrm{h}^{-1}\right)$; and (d) temperature anomaly (contours $\left.\mathrm{K}\right)$ and mixing ration anomaly (color shading); all plotted at times 0300, 1200, and 2100 UTC 19 Aug, during the intensifying phase of Typhoon Nuri (2008). 
outside the boundary layer (i.e., where $\mathbf{F}$ is small). Therefore, contours of $\Omega$ are approximate streamlines of the quasi-steady flow (Stoelinga 1996), which can be seen in the more matured phases of Nuri (Fig. 12c at 1200 and 2100 UTC 19 August), when also large heating tendency (green contours in Fig. 12c) and warmer and more moist air (Fig. 12d) are aligned near the eyewall. The flow vectors approximately follow the $\Omega$ contours as the latter sprout up from the top of the boundary layer and spread radially outward. Since

$$
\boldsymbol{\eta}_{a} \approx-\mathbf{j} \times \nabla_{r z} \Omega / r
$$

where $\nabla_{r z}$ is the gradient operator in the $r z$ plane and $\mathbf{j}$ is the azimuthal unit vector, the absolute vorticity vector approximately follows the streamlines, consistent with the outward leaning of $\boldsymbol{\eta}_{a}$ as positive PV is added below left of the heating. From Fig. 12c, it becomes clear that as radial inflow in the boundary layer carries higher $\Omega$ from outside into the eyewall, the contours are squeezed and high vertical component of $\boldsymbol{\eta}_{a}$ (i.e., $\zeta_{a}=r^{-1} \partial \Omega / \partial r$ ) is produced. As the $\Omega$ contours sprout up to rejoin those above the boundary layer where inflow is weaker, a vertical stratification in $\Omega$ (i.e., $-\partial \Omega / \partial z)$ is produced, resulting in very high radial component of $\boldsymbol{\eta}_{a}: \xi_{a}=-r^{-1} \partial \Omega / \partial z$. The ratio $\zeta_{a} / \xi_{a}=-(\partial \Omega / \partial r) /$ $(\partial \Omega / \partial z)$ is the slope of the $\Omega$ contour, and it is necessarily small of $O\left(z_{\mathrm{PBL}} / R_{\mathrm{MW}}\right)$, where $z_{\mathrm{PBL}}$ is the boundary layer height and $R_{\mathrm{MW}}$ is the radius of maximum wind; therefore, $\xi_{a}>>\zeta_{a}$ (Fig. 12a at 1200 and 2100 UTC 19 August). As the $\boldsymbol{\eta}_{a}$ leans outward following the $\Omega$ lines, it reinforces the PV production by condensation $1 / \rho\left(\boldsymbol{\eta}_{a} \cdot \nabla \dot{\theta}\right)$ since the heating is generally on the upper-right side. ${ }^{3}$

In a typhoon, there is then a tendency for maximal coupling between condensation, PV production, absolute vorticity intensification, upward outflow, and radial inflow within the boundary layer. How is the boundary layer inflow linked to PV and other variables? The azimuthal momentum equation (4.5) can be rewritten as (Riehl 1963)

\footnotetext{
${ }^{3}$ An equivalent interpretation is that, due to slantwise instability [chapter 12 of Emanuel (1994)], the atmosphere near the eyewall is approximately neutral in the direction of the absolute vorticity vector, so that $q_{e}=\boldsymbol{\eta}_{a} \cdot \nabla \theta_{e} \approx 0$, where $\theta_{e}$ is the equivalent potential temperature, and $q_{e}$ is the corresponding PV. It follows from (4.7) that contours of $\Omega$ and $\theta_{e}$ also coincide, and from (4.6): $d \theta_{e} / d t \approx 0$. Then, choosing the Ertel's surface to be $\theta_{e}$ in (4.1) and (4.2), the first term on the rhs of (4.2) vanishes. However, unlike with $\theta$, the solenoidal term $\rho^{-3} \nabla \theta_{e} \cdot(\nabla \rho \times \nabla p)$ does not identically vanish (Schubert et al. 2001). Nonetheless, we found that, in the case of Nuri, $\nabla \theta_{e} \cdot(\nabla \rho \times \nabla p)$ was also quite small of the same order as $d \theta_{e} / d t$. Therefore, outside the boundary layer, since $\nabla \times \mathbf{F}$ is small, $d q_{e} / d t \approx 0$, and since $q_{e} \approx 0$ in the boundary layer, $q_{e} \approx 0$ also in the eyewall (Emanuel 1986).
}

$\partial v / \partial t+(v / r) \partial v / \partial \phi+w \partial v / \partial z+\zeta_{a} u=-(\rho r)^{-1} \partial p / \partial \phi+F^{y}$

Writing $v=\langle v\rangle+v^{\prime}$ etc., where \langle\rangle is azimuthal averaging, and primes denote deviations from \langle\rangle , the azimuthally averaged form of (4.8) is

$$
\partial v / \partial t=-\zeta_{a} u-w \partial v / \partial z+E^{y}
$$

where $E^{y}=\left\langle F^{y}\right\rangle-\left\langle w^{\prime} \partial v^{\prime} / \partial z\right\rangle-\left\langle\zeta_{a}{ }^{\prime} u^{\prime}\right\rangle$ is the eddy and frictional terms lumped together, and the \langle\rangle symbol has been dropped from the other variables (i.e., $v=\langle v\rangle$ etc.). The contribution from $E^{y}$ is generally negative; the $r \times$ $\left\{-\left\langle w^{\prime} \partial v^{\prime} / \partial z\right\rangle\right\}$ is the "cloud torque" of Krishnamurti et al. (2007) relating to air parcel moving through cloud, and it is the dominant negative term of $E^{y}$ tending to deplete the angular momentum of the parcel as it moves inward into the storm. Xu and Wang (2010) found $E^{y}$ to be negligible in their simulations, which was also the case in the Nuri simulation. The magnitude of the term $-w \partial v / \partial z$ turns out to be also smaller than that of $-\zeta_{a} u$. Thus, (4.9) becomes

$$
\partial v / \partial t \approx-\zeta_{a} u
$$

In the radially inflowing layer near the surface (Fig. 12b), $u<0$, and $-\zeta_{a} u=|u| \zeta_{a}$ is positive and increases rapidly as the inflowing air approaches the eyewall because the $z$-component relative vorticity $\zeta=\partial v / \partial r+v / r$ becomes large. Figure 13 plots $-\zeta_{a} u$ (shading) with contours of the azimuthal wind speed at $z=10 \mathrm{~m}$; showing intensified $v$ and eyewall contraction with large inflow of $\zeta_{a}$, indicative of the coupling nature of $u$ and $\zeta_{a}$ with $v$ in (4.10) (Xu and Wang, 2010). Because surface $v$ intensifies, the radial component of the relative vorticity $\xi_{a} \approx-\partial v / \partial z$ also intensifies, and the $\boldsymbol{\eta}_{a}$ leans outward. Figure 14 plots the time series of $\left(\xi_{a}, \zeta_{a}\right) / f$, surface rain rate, $-\zeta_{a} u, 1 / \rho\left(\boldsymbol{\eta}_{a} \cdot \nabla \dot{\theta}\right)$ and $\mathrm{PV}$ near the eyewall. During intensification, $\xi_{a}$ is many times larger than $\zeta_{a}$. The $\xi_{a}$ correlates well with the diabatic heating, which in turn leads the rain rate by about $12 \mathrm{~h}$ (Fig. 14a). ${ }^{4}$ The model indicates strong diabatic heating at 1200 UTC 19 August and 1200 UTC 20 August, coinciding with peaks in $\xi_{\mathrm{a}}$. These variations confirm that outward leaning of $\boldsymbol{\eta}_{a}$ and PV production by condensation reinforce each other. Meanwhile, PV continues to accumulate up to its peak at 1200 UTC 20 August, and is

\footnotetext{
${ }^{4}$ That yields an effective precipitating speed of only $0.1 \mathrm{~m} \mathrm{~s}^{-1}$ over approximately $5-\mathrm{km}$ height as precipitation occurs mainly over the region of intense updraft where $w \cong 1 \mathrm{~m} \mathrm{~s}^{-1}$ (Fig. 10), of the same order as the terminal speeds of precipitating particles (Locatelli and Hobbs 1974).
} 

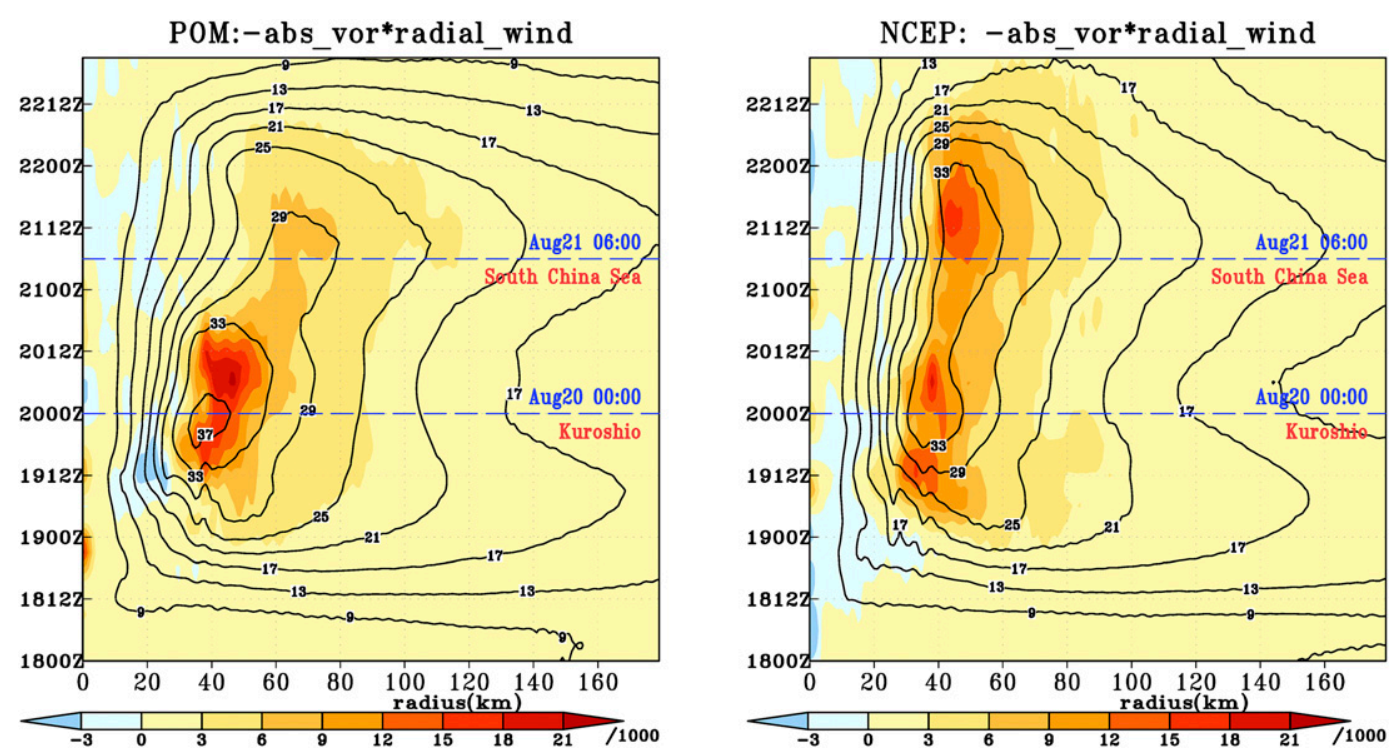

FIG. 13. Contours of the azimuthally averaged azimuthal tangential wind speed $\left(\mathrm{m} \mathrm{s}^{-1}\right)$ at $z=10 \mathrm{~m}$ superimposed on color shading of the term $-\zeta_{a} u\left(\mathrm{~m} \mathrm{~s}^{-2}\right)$ in the azimuthally averaged momentum equation, depth averaged in the surface $1 \mathrm{~km}$ approximately within the boundary layer and plotted as a function of radial distance (km; the abscissa) and time (in August 2008; the ordinate) for the (left) pom_KS and (right) ncep_KS experiments.

well correlated with $\zeta_{a}$ (Fig. 14b). This PV rise is accompanied by $-\zeta_{a} u$, which is nearly in phase with, but slightly lags $\xi_{a}$ and heating.

In summary, the intensification of Typhoon Nuri may be explained as a positive feedback loop (Fig. 15). In the early stages, some favorable perturbations perhaps cyclonic anomalies and convection over warm SST generate condensation-heating clusters in the low troposphere (Fig. 12c). The clusters favor PV production of air parcels with $\boldsymbol{\eta}_{a}$ that leans clockwise (in the $r z$ plane) into the heating from below left. The $\boldsymbol{\eta}_{a}$ from above the heating implies a strong anticyclonic vorticity that is unlikely, ${ }^{5}$ while $\boldsymbol{\eta}_{a}$ originating from below right would yield anticyclonic azimuthal flow opposing the cyclone; neither are conducive to PV growth. The numerical model indicates that growth of PV is primarily derived from strong increases in $\left|\boldsymbol{\eta}_{a}\right|$ (Fig. 14) and, hence, also in the squeezing of the $\Omega$ contours in the $r z$ plane [(4.7)]. The updraft intensifies below left of the heating where these contours crowd just above the boundary layer. Radial inflow is, therefore, forced in the boundary layer spiraling toward the center, and the coupling of the radial flow with $\zeta_{a}$ enhances the azimuthal velocity $v$ near the surface [(4.10)]. The $\xi_{a}$ intensifies, producing a further clockwise leaning of $\boldsymbol{\eta}_{a}$ that favors the PV production by heating, thus completing the positive feedback loop. It is important to realize that, while we have chosen

\footnotetext{
${ }^{5}$ Moreover flow tends to be centrifugally unstable.
}

lower-tropospheric heating as the basic starting point, the loop can be initiated from any of the processes described above, provided that the supply of enthalpy from the warm ocean is available. The ocean clearly plays an important role in the case of Nuri. It now becomes clear that, by comparing the pom_KS and ncep_ KS experiments in Fig. 11, the reason why the latter failed to predict the correct timing of Nuri at 0000 UTC 20 August was because it failed to account for the strong diabatic PV production over the warm pool and the Kuroshio.

\section{Conclusions and discussion}

Typhoon Nuri formed on 18 August 2008 in the western North Pacific, east of the Philippines, and traversed northwestward over the Kuroshio in the Luzon Strait where it intensified to a category 3 typhoon. The storm weakened as it passed over the South China Sea and made landfall in Hong Kong as a category 1 typhoon on 22 August. This work used the WRF numerical model to study Nuri, focusing on understanding the dominant processes that caused the intensity change. The sensitivity of intensity and track to different microphysics schemes was examined by keeping the SST fixed. Then the sensitivity to different SSTs was studied by keeping the microphysics scheme fixed. The SST datasets included two reanalysis data: NCEP SST and GHRSST, and a third set from the POM North Pacific Ocean model. A summary of our main findings follows: 
(a)

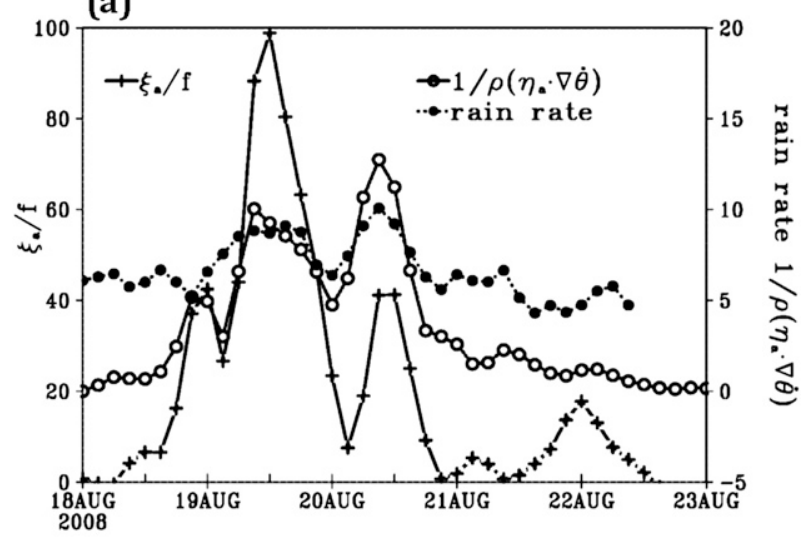

(b)

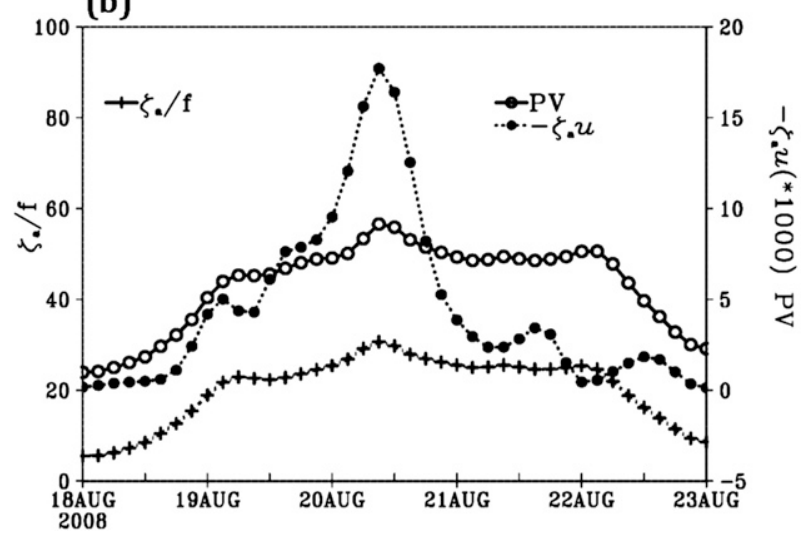

FIG. 14. Time series of (a) $\xi_{a} / f, 1 / \rho\left(\boldsymbol{\eta}_{a} \cdot \nabla \dot{\theta}\right)$, and surface rain rate $\left(\mathrm{mm} \mathrm{h}^{-1}\right)$, and (b) $\zeta_{a} / f,-\zeta_{a} u$, and PV. The $-\zeta_{a} u$ was calculated at $r=50 \mathrm{~km}$ and averaged from $z=0$ to $1 \mathrm{~km} ; \xi_{a} / f, \zeta_{a} / f$, and PV were averaged from $r=30-70 \mathrm{~km}$ and $z=0-3 \mathrm{~km}, 1 / \rho\left(\boldsymbol{\eta}_{a} \cdot \nabla \dot{\theta}\right)$ from $r=$ $30-70 \mathrm{~km}$ and $z=0-1.5 \mathrm{~km}$, and the rain rate over a radius of $200 \mathrm{~km}$ from the center. The rain rate has been shifted forward in time by $12 \mathrm{~h}$ (see text).

1) The simulated intensity of Nuri agreed well with observations when the POM SST was used, reaching a peak intensity over the warm Kuroshio, while using NCEP and GHR SSTs yielded large errors both in intensity and the timing of maximum intensity.

2) The intensity change of Nuri was relatively insensitive to different microphysics schemes used in WRF, but largely depended on the spatial distribution of the SST, which in turn was dynamically dependent on the responses to the passing storm of the two ocean basins: the Philippines Sea of the western Pacific and the South China Sea.

3) The $Z_{26}$ shallowed rapidly by half from the western Pacific to the South China Sea. In the case of Nuri, this and the strong mixing caused by the ocean's inertial resonance with the wind produced strong cooling in SCS, causing the storm to weaken.

4) Wind shear was not the main factor controlling the intensity change of Nuri, but it determined the precipitation pattern that was asymmetric downshear left in agreement with TRMM observation, as well as with the composite analysis of Chen et al. (2006).

5) The different simulated intensity changes of Nuri when using different SSTs can be understood by the mutual reinforcement of heating and outward leaning of the absolute vorticity vector in PV production; a positive feedback loop between PV production, squeezing of total angular momentum contours, boundary layer inflow, and intensification of the azimuthal wind was described.

With regard the last point above, ocean dynamics dictated strong SST differences left (warmer) and right (cooler) of Nuri over the western North Pacific (Fig. 6, bottom-right panel) that, together with the northeasterly shear, would tend to favor updraft over warmer water and, therefore, intensification, which was indeed observed. Raymond and Carrillo (2011) explained that overlapping closed circulations with height developed left of the shear, providing a deep protected region where rapid spinup of Nuri could develop by strong convection and boundary layer absolute-vorticity convergence, consistent with the positive feedback loop. It will be an interesting future study to explore the generality of these different processes based on one storm.

This study shows that the intensity change of Nuri was controlled by wind-ocean resonance and the rapid change in the ocean's $Z_{26}$ across the Kuroshio in the Luzon Strait. Of the 129 typhoons that went through the Luzon Strait into the South China Sea during 1951-2013 (Fig. 2), the majority (96) reached their peak intensities east of Luzon and then weakened in the South China Sea similar to Typhoon Nuri, suggesting that their behaviors may depend on some common underlying environmental parameters that favor weakening in the South China Sea. First, as in the case of Nuri, the July-AugustSeptember (JAS) climatology shows thinner $Z_{26}$ in the South China Sea than in the western North Pacific. Second, a majority (64\%) of typhoons were fast moving $\left(>4.4 \mathrm{~m} \mathrm{~s}^{-1}\right.$; Zhao et al. 2008) and moved westnorthwestward into higher- $f$ latitudes, making them supercritical (e.g., Gill 1982) and favoring stronger windocean resonance in the South China Sea. Third, the background circulation in the northern South China Sea is cyclonic (Xu and Oey 2014), favoring a concentration of inertial energy in the upper layer, hence, greater mixing and cooling (Sun et al. 2015). Fourth, while in the case of Nuri the large-scale wind shear may not be the main factor controlling the intensity change, the climatological wind shear increases from east to west into the South China Sea (Chen et al. 2006). Finally, strong 


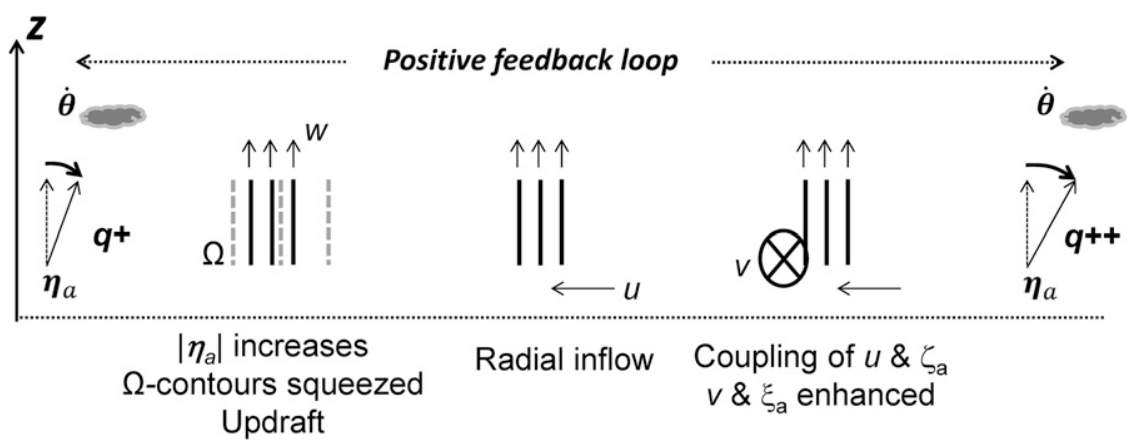

FIG. 15. A schematic of the positive feedback between PV production by heating $\dot{\theta}$, $\boldsymbol{\eta}_{a}$ alignment along $\nabla \dot{\theta}$, squeezing of total angular momentum $\Omega$ contours, updraft, boundary layer inflow $u$, and intensification of the azimuthal wind $v$.

internal tides develop in the northern South China Sea (Ramp et al. 2010), generating strong mixing and cooling. The relative proportions of typhoons that intensified either east of Luzon or in the South China Sea can also vary interannually. We plan to explore these in the future.

Acknowledgments. We thank two anonymous reviewers and Editor Dr. Patrick Harr for their comments, which improved the manuscript. We thank reviewer 1 for bringing to our attention the work by Raymond and Carrillo (2011). Part of this work was completed while JS conducted her summer (2014) research at NCU, Taiwan. LYO is grateful for the award he received from the Taiwan's Foundation for the Advancement of Outstanding Scholarship, and wishes to thank Mr. Simon Chao for providing Fig. 2. The research was in part supported by the National Science Council of Taiwan. JS thanks her Tsinghua adviser, Prof. F.-H. Xu, for guidance and support through the Tsinghua University Initiative Scientific Research Program (Project 20131089356). Calculations were conducted at the National Central University's ATOP cluster, as well as at the Tsinghua University's server Tansuo100.

\section{REFERENCES}

Atlas, R., R. N. Hoffman, J. Ardizzone, S. M. Leidner, J. C. Jusem, D. K. Smith, and D. Gombos,, 2011: A cross-calibrated, multiplatform ocean surface wind velocity product for meteorological and oceanographic applications. Bull. Amer. Meteor. Soc., 92, 157-174, doi:10.1175/2010BAMS2946.1.

Braun, S. A., and W. K. Tao, 2000: Sensitivity of high-resolution simulations of Hurricane Bob (1991) to planetary boundary layer parameterizations. Mon. Wea. Rev., 128, 3941-3961, doi:10.1175/1520-0493(2000)129<3941:SOHRSO > 2.0.CO;2.

Chen, S. S., J. A. Knaff, and F. D. Marks Jr., 2006: Effects of vertical wind shear and storm motion on tropical cyclone rainfall asymmetries deduced from TRMM. Mon. Wea. Rev., 134, 3190-3208, doi:10.1175/MWR3245.1.

Davis, C., and Coauthors, 2008: Prediction of landfalling hurricanes with the advanced hurricane WRF model. Mon. Wea. Rev., 136, 1990-2005, doi:10.1175/2007MWR2085.1.
DeMaria, M., 1996: The effect of vertical shear on tropical cyclone intensity change. J. Atmos. Sci., 53, 2076-2087, doi:10.1175/ 1520-0469(1996)053<2076:TEOVSO > 2.0.CO;2.

_ , and J. Kaplan, 1994: Sea surface temperature and the maximum intensity of Atlantic tropical cyclones. J. Climate, 7, 1324-1334, doi:10.1175/1520-0442(1994)007<1324:SSTATM>2.0.CO;2.

_ mentum fluxes and tropical cyclone intensity change. J. Atmos. Sci., 50, 1133-1147, doi:10.1175/1520-0469(1993)050<1133: ULEAMF $>2.0 . \mathrm{CO} ; 2$.

Efstathiou, G. A., N. M. Zoumakis, D. Melas, C. J. Lolis, and P. Kassomenos, 2013: Sensitivity of WRF to boundary layer parameterizations in simulating a heavy rainfall event using different microphysical schemes: Effect on large-scale processes. Atmos. Res., 132-133, 125-143, doi:10.1016/j.atmosres.2013.05.004.

Elsner, J. B., and K.-B. Liu, 2003: Examining the ENSO-typhoon hypothesis. Climate Res., 25, 43-54, doi:10.3354/cr025043.

Emanuel, K. A., 1986: An air-sea interaction theory for tropical cyclones. Part I: Steady-state maintenance. J. Atmos. Sci., 43, 585605, doi:10.1175/1520-0469(1986)043<0585:AASITF>2.0.CO;2.

— 1994: Atmospheric Convection. Oxford University Press, 580 pp. , 1999: Thermodynamic control of hurricane intensity. Nature, 401, 665-669, doi:10.1038/44326.

_ C. DesAutels, C. Holloway, and R. Korty, 2004: Environmental control of tropical cyclone intensity. J. Atmos. Sci., 61, 843-858, doi:10.1175/1520-0469(2004)061<0843:ECOTCI >2.0.CO;2.

Ertel, H., 1942: Ein neuer hydrodynamischer Wirbelsatz. (A new hydrodynamical vorticity equation). Meteor. Z., 59, 277-281.

Ferrier, B. S., Y. Jin, Y. Lin, T. Black, E. Rogers, and G. DiMego, 2002: Implementation of a new grid-scale cloud and precipitation scheme in the NCEP Eta model. Preprints, 19th Conf. on Weather Analysis and Forecasting/15th Conf. on Numerical Weather Prediction, San Antonio, TX, Amer. Meteor. Soc., 10.1. [Available online at https://ams.confex.com/ ams/SLS_WAF_NWP/techprogram/paper_47241.htm.]

Frank, W. M., and E. A. Ritchie, 1999: Effects of environmental flow upon tropical cyclone structure. Mon. Wea. Rev., 127, 2044-2061, doi:10.1175/1520-0493(1999)127<2044: EOEFUT>2.0.CO;2.

Gall, R., J. Franklin, F. Marks, E. N. Rappaport, and F. Toepfer, 2013: The Hurricane Forecast Improvement Project. Bull. Amer. Meteor. Soc., 94, 329-343, doi:10.1175/BAMS-D-12-00071.1.

Gill, A. E., 1982: Atmosphere-Ocean Dynamics. Academic Press, 662 pp.

Goldenberg, S. B., C. Landsea, A. M. Mestas-Nunez, and W. M. Gray, 2001: The recent increase in Atlantic hurricane activity. Science, 293, 474-479, doi:10.1126/science. 1060040. 
Green, B. W., and F. Zhang, 2013: Impacts of air-sea flux parameterizations on the intensity and structure of tropical cyclones. Mon. Wea. Rev., 141, 2308-2324, doi:10.1175/MWR-D-12-00274.1.

Hausman, S. A., K. V. Ooyama, and W. H. Schubert, 2006: Potential vorticity structure of simulated hurricanes. J. Atmos. Sci., 63, 87-108, doi:10.1175/JAS3601.1.

Hendricks, E. A., M. S. Peng, and T. Li, 2013: Evaluation of multiple dynamic initialization schemes for tropical cyclone prediction. Mon. Wea. Rev., 141, 4028-4048, doi:10.1175/ MWR-D-12-00329.1.

Hill, K. A., and G. M. Lackmann, 2009: Influence of environmental humidity on tropical cyclone size. Mon. Wea. Rev., 137, 32943315, doi:10.1175/2009MWR2679.1.

Holland, G. J., 1980: An analytic model of the wind and pressure profiles in hurricanes. Mon. Wea. Rev., 108, 1212-1218, doi:10.1175/1520-0493(1980)108<1212:AAMOTW>2.0.CO;2.

Holton, J. R., 2004: An Introduction to Dynamic Meteorology. Academic Press, 535 pp.

Hong, S. Y., and J. O. J. Lim, 2006: The WRF single-moment 6-class microphysics scheme (WSM6). J. Korean Meteor. Soc., 42 (2), 129-151.

—_, Y. Noh, and J. Dudhia, 2006: A new vertical diffusion package with an explicit treatment of entrainment processes. Mon. Wea. Rev., 134, 2318-2341, doi:10.1175/MWR3199.1.

Houze, R. A., S. S. Chen, B. F. Smull, W. C. Lee, and M. M. Bell, 2007: Hurricane intensity and eyewall replacement. Science, 315, 1235-1239, doi:10.1126/science.1135650.

Huang, S.-M., and L.-Y. Oey, 2015: Right-side cooling and phytoplankton bloom in the wake of a tropical cyclone. J. Geophys. Res. Oceans, doi:10.1002/2015JC010896, in press.

Jones, S. C., 1995: The evolution of vortices in vertical shear. I: Initially barotropic vortices. Quart. J. Roy. Meteor. Soc., 121, 821-851, doi:10.1002/qj.49712152406.

Kain, J. S., 2004: The Kain-Fritsch convective parameterization: An update. J. Appl. Meteor., 43, 170-181, doi:10.1175/ 1520-0450(2004)043<0170:TKCPAU > 2.0.CO;2.

—, and J. M. Fritsch, 1990: A one-dimensional entraining/ detraining plume model and its application in convective parameterization. J. Atmos. Sci., 47, 2784-2802, doi:10.1175/ 1520-0469(1990)047<2784:AODEPM > 2.0.CO;2.

Kaplan, J., and M. DeMaria, 2003: Large-scale characteristics of rapidly intensifying tropical cyclones in the North Atlantic basin. Wea. Forecasting, 18, 1093-1108, doi:10.1175/ 1520-0434(2003)018<1093:LCORIT > 2.0.CO;2.

Kessler, E., 1969: On the Distribution and Continuity of Water Substance in Atmospheric Circulation. Meteor. Monogr., No. 32, Amer. Meteor. Soc., 84 pp.

Krishnamurti, T. N., L. Stefanova, L. Watson, and S. Pattnaik, 2007: Addressing hurricanes intensity through angular momentum and scale energetics approaches. Pure Appl. Geophys., 164, 1429-1441, doi:10.1007/s00024-007-0238-z.

Kunze, E., 1985: Near-inertial wave propagation in geostrophic shear. J. Phys. Oceanogr., 15, 544-565, doi:10.1175/ 1520-0485(1985)015<0544:NIWPIG > 2.0.CO;2.

— R. W. Schmitt, and J. M. Toole, 1995: The energy balance in a warm-core ring's near-inertial critical layer. J. Phys. Oceanogr., 25, 942-957, doi:10.1175/1520-0485(1995)025<0942: TEBIAW $>2.0 . \mathrm{CO} ; 2$.

Landsea, C. W., 2000: Climate variability of tropical cyclones: Past, present and future. Storms, R. A. Pielke Sr. and R. A Pielke Jr., Eds., Routledge, 220-241.

Lee, C.-Y., and S. S. Chen, 2012: Symmetric and asymmetric structures of hurricane boundary layer in coupled atmosphere-wave-ocean models and observations. J. Atmos. Sci., 69, 3576-3594, doi:10.1175/JAS-D-12-046.1.

$\longrightarrow$, and - 2014: Stable boundary layer and its impact on tropical cyclone structure in a coupled atmosphere-ocean model. Mon. Wea. Rev., 142, 1927-1944, doi:10.1175/MWR-D-13-00122.1.

Leipper, D. F., and D. Volgenau, 1972: Hurricane heat potential of the Gulf of Mexico. J. Phys. Oceanogr., 2, 218-224, doi:10.1175/ 1520-0485(1972)002<0218:HHPOTG > 2.0.CO;2.

$\mathrm{Li}, \mathrm{X}$., and Z. Pu, 2008: Sensitivity of numerical simulation of early rapid intensification of Hurricane Emily (2005) to cloud microphysical and planetary boundary layer parameterizations. Mon. Wea. Rev., 136, 4819-4838,doi:10.1175/2008MWR2366.1.

Lin, I.-I., C.-C. Wu, I.-F. Pun, and D.-S. Ko, 2008: Upper-ocean thermal structure and the western North Pacific category-5 typhoons. Part I: Ocean features and the category-5 typhoons' intensification. Mon. Wea. Rev., 136, 3288-3306, doi:10.1175/2008MWR2277.1.

Lin, Y., and B. A. Colle, 2011: A new bulk microphysical scheme that includes riming intensity and temperature-dependent ice characteristics. Mon. Wea. Rev., 139, 1013-1035, doi:10.1175/ 2010MWR3293.1.

Locatelli, J. D., and P. V. Hobbs, 1974: Fall speeds and masses of solid precipitation particles. J. Geophys. Res., 79, 2185-2197, doi:10.1029/JC079i015p02185.

Lord, S. J., H. E. Willoughby, and J. M. Piotrowicz, 1984: Role of a parameterized ice-phase microphysics in an axisymmetric, nonhydrostatic tropical cyclone model. J. Atmos. Sci., 41, 2836-2848, doi:10.1175/1520-0469(1984)041<2836:ROAPIP > 2.0.CO;2.

Lueck, R., and T. Osborn, 1986: The dissipation of kinetic energy in a warm-core ring. J. Geophys. Res., 91, 803-818, doi:10.1029/ JC091iC01p00803.

Marks, F. D., and L. K. Shay, 1998: Landfalling tropical cyclones: Forecast problems and associated research opportunities. Bull. Amer. Meteor. Soc., 79, 305-323, doi:10.1175/ 1520-0477(1998)079<0305:LTCFPA > 2.0.CO;2.

Marteau, R., Y. Richard, B. Pohl, C. C. Smith, and T. Castel, 2015: High-resolution rainfall variability simulated by the WRF RCM: Application to eastern France. Climate Dyn., 44, 1093 1107, doi:10.1007/s00382-014-2125-5.

Michalakes, J., S. Chen, J. Dudhia, L. Hart, J. Klemp, J. Middlecoff, and W. Skamarock, 2001: Development of a next generation regional weather research and forecast model. Developments in Teracomputing: Proceedings of the Ninth ECMWF Workshop on the Use of High Performance Computing in Meteorology, Vol. 1, World Scientific, 269-276.

Montgomery, M. T., and R. K. Smith, 2012: The genesis of Typhoon Nuri as observed during the Tropical Cyclone Structure 2008 (TCS08) field experiment-Part 2: Observations of the convective environment. Atmos. Chem. Phys., 12, 4001-4009, doi:10.5194/acp-12-4001-2012.

Oey, L.-Y., T. Ezer, D.-P. Wang, S.-J. Fan, and X.-Q. Yin, 2006: Loop Current warming by Hurricane Wilma. Geophys. Res. Lett., 33, L08613, doi:10.1029/2006GL025873.

,,,--- X.-Q. Yin, and S.-J. Fan, 2007: Hurricane-induced motions and interaction with ocean currents. Cont. Shelf Res., 27, 1249-1263, doi:10.1016/j.csr.2007.01.008.

_ M. Inoue, R. Lai, X. H. Lin, S. E. Welsh, and L. J. Rouse Jr., 2008: Stalling of near-inertial waves in a cyclone. Geophys. Res. Lett., 35, L12604, doi:10.1029/2008GL034273.

—, Y.-L. Chang, Y.-C. Lin, M.-C. Chang, F.-H. Xu, and H.-F. Lu, 2013: ATOP-The Advanced Taiwan Ocean Prediction System based on the mpiPOM. Part 1: Model descriptions, analyses and results. Terr. Atmos. Oceanic Sci., 24, 137-158, doi:10.3319/TAO.2012.09.12.01(Oc). 
, S. Varlamov, and Y. Miyazawa, 2014: Cross flows in the Taiwan Strait in winter. J. Phys. Oceanogr., 44, 801-817, doi:10.1175/JPO-D-13-0128.1.

Pedlosky, J., 1982: Geophysical Fluid Dynamics. Springer-Verlag, $710 \mathrm{pp}$.

Pennelly, C., G. Reuter, and T. Flesch, 2014: Verification of the WRF model for simulating heavy precipitation in Alberta. Atmos. Res., 135-136, 172-192, doi:10.1016/j.atmosres.2013.09.004.

Pielke, R. A., and C. W. Landsea, 1999: La Niña, El Niño, and Atlantic hurricane damages in the United States. Bull. Amer. Meteor. Soc., 80, 2027-2033, doi:10.1175/1520-0477(1999)080<2027: LNAENO $>2.0 . \mathrm{CO} ; 2$.

Price, J. F., 1981: Upper ocean response to a hurricane. J. Phys. Oceanogr., 11, 153-175, doi:10.1175/1520-0485(1981)011<0153 UORTAH $>2.0 . \mathrm{CO} ; 2$

—, T. B. Sanford, and G. Z. Forristall, 1994: Forced stage response to a moving hurricane. J. Phys. Oceanogr., 24, 233-260, doi:10.1175/1520-0485(1994)024<0233:FSRTAM >2.0.CO;2.

Ramp, S. R., Y. J. Yang, and F. L. Bahr, 2010: Characterizing the nonlinear internal wave climate in the northeastern South China Sea. Nonlinear Processes Geophys., 17, 481-498, doi:10.5194/ npg-17-481-2010.

Rappaport, E. N., and Coauthors, 2009: Advances and challenges at the National Hurricane Center. Wea. Forecasting, 24, 395 419, doi:10.1175/2008WAF2222128.1.

Raymond, D. J., 1992: Nonlinear balance and potential-vorticity thinking at large Rossby number. Quart. J. Roy. Meteor. Soc., 118, 987-1015, doi:10.1002/qj.49711850708.

_ , and L. Carrillo, 2011: The vorticity budget of developing Typhoon Nuri (2008). Atmos. Chem. Phys., 11, 147-163, doi:10.5194/acp-11-147-2011.

Riehl, H., 1963: Some relations between wind and thermal structure of steady state hurricanes. J. Atmos. Sci., 20, 276-287, doi:10.1175/1520-0469(1963)020<0276:SRBWAT $>2.0$.CO;2.

Rios-Berrios, R., T. Vukicevic, and B. Tang, 2014: Adopting model uncertainties for tropical cyclone intensity prediction. Mon. Wea. Rev., 142, 72-78, doi:10.1175/MWR-D-13-00186.1.

Rogers, R., and Coauthors, 2006: The intensity forecasting experiment: A NOAA multiyear field program for improving tropical cyclone intensity forecasts. Bull. Amer. Meteor. Soc., 87, 1523-1537, doi:10.1175/BAMS-87-11-1523.

Schade, L. R., and K. A. Emanuel, 1999: The ocean's effect on the intensity of tropical cyclones: Results from a simple coupled atmosphere-ocean model. J. Atmos. Sci., 56, 642-651, doi:10.1175/ 1520-0469(1999)056<0642:TOSEOT $>2.0 . C O ; 2$.

Schubert, W. H., S. A. Hausman, M. Garcia, K. V. Ooyama, and H. C. Kuo, 2001: Potential vorticity in a moist atmosphere. J. Atmos. Sci., 58, 3148-3157, doi:10.1175/1520-0469(2001)058<3148: PVIAMA $>2.0 . \mathrm{CO} ; 2$.

_, E. Ruprecht, R. Hertenstein, R. Ferreira, R. Taft, C. Rozoff, P. Ciesielski, and H.-C. Kuo, 2004: English translations of twentyone of Ertel's papers on geophysical fluid dynamics. Meteor. Z., 13, 527-576, doi: 10.1127/0941-2948/2004/0013-0527.

Shu, Y., D. Wang, J. Zhu, and S. Peng, 2011: The 4-D structure of upwelling and Pearl River plume in the northern South China Sea during summer 2008 revealed by a data assimilation model. Ocean Modell., 36, 228-241, doi:10.1016/j.ocemod.2011.01.002.

Stoelinga, M. T., 1996: A potential vorticity-based study of the role of diabatic heating and friction in a numerically simulated baroclinic cyclone. Mon. Wea. Rev., 124, 849-874, doi:10.1175/ 1520-0493(1996)124<0849:APVBSO > 2.0.CO;2.
Sun, J., L. Y. Oey, R. Chang, F. Xu, and S. M. Huang, 2015: Ocean response to typhoon Nuri (2008) in western Pacific and South China Sea. Ocean Dyn., 65, 735-749, doi:10.1007/s10236-015-0823-0.

Tao, W. K., J. J. Shi, S. S. Chen, S. Lang, P.-L. Lin, S.-Y. Hong, C. P. Lidard, and A. Hou, 2011: The impact of microphysical schemes on hurricane intensity and track. Asia-Pac. J. Atmos. Sci., 47, 1-16, doi:10.1007/s13143-011-1001-z.

Wang, D. P., and L. Y. Oey, 2008: Hindcast of waves and currents in Hurricane Katrina. Bull. Amer. Meteor. Soc., 89, 487-495, doi:10.1175/BAMS-89-4-487.

Wang, D., W. Zhuang, S.-P. Xie, J. Hu, Y. Shu, and R. Wu, 2012: Coastal upwelling in summer 2000 in the northeastern South China Sea. J. Geophys. Res., 117, C04009, doi:10.1029/ 2011JC007465.

Wang, W., and N. L. Seaman, 1997: A comparison study of convective parameterization schemes in a mesoscale model. Mon. Wea. Rev., 125, 252-278, doi:10.1175/1520-0493(1997)125<0252: ACSOCP $>2.0 . \mathrm{CO} ; 2$.

Wang, Y., 2002: An explicit simulation of tropical cyclones with a triply nested movable mesh primitive equation model: TCM3. Part II: Model refinements and sensitivity to cloud microphysics parameterization. Mon. Wea. Rev., 130, 3022-3036, doi:10.1175/1520-0493(2002)130<3022:AESOTC >2.0.CO;2. , and G. J. Holland, 1996: Tropical cyclone motion and evolution in vertical shear. J. Atmos. Sci., 53, 3313-3332, doi:10.1175/1520-0469(1996)053<3313:TCMAEI >2.0.CO;2.

Wentz, F. J., C. Gentemann, D. Smith, and D. Chelton, 2000: Satellite measurements of sea surface temperature through clouds. Science, 288, 847-850, doi:10.1126/science.288.5467.847.

Willoughby, H. E., H.-L. Jin, S. J. Lord, and J. M. Piotrowicz, 1984: Hurricane structure and evolution as simulated by an axisymmetric, nonhydrostatic numerical model. J. Atmos. Sci., 41, 1169-1186, doi:10.1175/1520-0469(1984)041<1169:HSAEAS > 2.0.CO;2.

Xu, F.-H., and L.-Y. Oey, 2014: State analysis using the Local Ensemble Transform Kalman Filter (LETKF) and the three-layer circulation structure of the Luzon Strait and the South China Sea. Ocean Dyn., 64, 905-923, doi:10.1007/s10236-014-0720-y.

$\mathrm{Xu}$, J., and Y. Wang, 2010: Sensitivity of tropical cyclone inner-core size and intensity to the radial distribution of surface entropy flux. J. Atmos. Sci., 67, 1831-1852, doi:10.1175/2010JAS3387.1.

Yin, X. Q., and L. Y. Oey, 2007: Bred-ensemble ocean forecast of Loop Current and rings. Ocean Modell., 17, 300-326, doi:10.1016/ j.ocemod.2007.02.005.

Zeng, Z., Y. Wang, and C.-C. Wu, 2007: Environmental dynamical control of tropical cyclone intensity-An observational study. Mon. Wea. Rev., 135, 38-59, doi:10.1175/MWR3278.1.

Zhang, D. L., and C. Q. Kieu, 2005: Shear-forced vertical circulations in tropical cyclones. Geophys. Res. Lett., 32, L13822, doi:10.1029/2005GL023146.

Zhang, F., Y. Weng, J. A. Sippel, Z. Meng, and C. H. Bishop, 2009: Cloud-resolving hurricane initialization and prediction through assimilation of Doppler radar observations with an ensemble Kalman filter. Mon. Wea. Rev., 137, 2105-2125, doi:10.1175/2009MWR2645.1.

Zhao, H., D.-L. Tang, and Y. Wang, 2008: Comparison of phytoplankton blooms triggered by two typhoons with different intensities and translation speeds in the South China Sea. Mar. Ecol. Prog. Ser., 365, 57-65, doi:10.3354/meps07488.

Zhu, T., and D.-L. Zhang, 2006: Numerical simulation of Hurricane Bonnie (1998). Part II: Sensitivity to varying cloud microphysical processes. J. Atmos. Sci., 63, 109-126, doi:10.1175/JAS3599.1. 